\title{
Organizational Design and Restructuring in Response to Crises: Lessons from Computational Modeling and Real-World Cases
}

\author{
Zhiang (John) Lin, Xia Zhao, Kiran M. Ismail \\ School of Management, University of Texas at Dallas, Richardson, Texas 75083 \\ \{zlin@utdallas.edu,xia.zhao@utdallas.edu,kiranm@utdallas.edu\} \\ Kathleen M. Carley \\ Institute for Software Research International, Carnegie Mellon University, Pittsburgh, Pennsylvania 15213, kathleen.carley@cmu.edu
}

\begin{abstract}
$\mathrm{O}$ rganizations are occasionally faced with technology-based and accident-triggered crises that may cause costly disasters if not handled properly. Questions arise: How should organizations, with their complex processes and human involvement, be designed if they are to perform well in such crises? Would organizations benefit from structural changes during crises? From a neo-information processing perspective that views organizations as composed of cognitively restricted, socially situated, and task-oriented actors, we argue that the causes and consequences of crises may be better understood through the systematic examination of both environmental and organizational factors. We address our research questions using a rather unique approach: a matched analysis of 80 real organizational cases and 80 computer-simulated organizations. The findings show that a crisis can present critical challenges to organizational performance both externally and internally, and that there is no design guarantee that a high-performing organization will continue to perform well during a crisis situation. In addition, when organizations restructure to adapt to crisis situations, they often face the serious challenges of having to understand not only the external environment, but also organizational design traps.
\end{abstract}

Key words: organizational performance; organizational design; computational modeling; real-crisis cases

Whether theories of organization can be applied to nonconventional events or crisis situations has largely been assumed but certainly not fully explored (Carley and Harrald 1997, Marcus and Nichols 1999, Perrow 1994). Crises are important organizational phenomena not only because they can cause severe consequences or even devastating disasters if not properly handled, but also because they are becoming inevitable, given the increasingly complex and technology-oriented processes of organizations (Perrow 1984, Shrivastava 1987). The bulk of research in crisis management, however, has relied heavily on conventional case methods and has focused exclusively on preventing crises, assuming that crises are avoidable, once-in-a-lifetime events. Often, findings have become listings of rhetorical suggestions, lacking theoretical backgrounds and quantitative foundations (Pauchant and Douville 1993).

Crises faced by organizations often have their roots in both the external environment and in malfunctions within the organization (March and Simon 1958, Perrow 1984). An example may be the incident, which is described below, of an Iran Air flight being shot down by the USS Vincennes (Rochlin 1991). We believe that there may be a systematic approach to exploring organizational performance during crises through observable factors including expertise, organizational design, and task environment (Carley and Lin 1997, Hollenbeck et al. 1995, Levinthal and Warglien 1999, Pearson and Mitroff 1993).

To the extent that crises are indeed inevitable and that there exists systematicity to their outcomes, this study intends to ask not how to avoid crises, but how to design an organization for better performance during a crisis. Reframing the question in this way gives rise to an entirely new set of concerns: Is the organizational design that exhibits high performance during a crisis also a good performer under noncrisis conditions? Is it reasonable for organizations to design for crises, or should organizations alter their designs when faced with a crisis? In other words, is dynamic adaptation called for? Furthermore, if organizations do restructure, what would be the most effective new structure?

To address these research questions, we take a neo-information processing perspective and conduct a matched analysis: 80 artificial organizations from a computational model that incorporates aspects of task environment, organizational design, and crises; and 80 real-world cases in which organizations were faced with actual crises. Such a matched analysis serves two purposes. First, it allows us to provide a fine-grained theory and an empirical test for understanding the causes of crises and the organizational design that can help mitigate them. 
Second, it provides an opportunity to address the issue of organizational adaptation during crises through a series of "what if" simulation experiments, therefore providing prescriptive theoretical directions for effective crisis management.

\section{Research Background}

Organizations are increasingly reliant on technology, which takes the forms of not just machines and tools, but also of management processes and practices (Pauchant and Douville 1993, Pearson and Clair 1998). Malfunctions or substandard conditions can happen, and can cause unintended uncertainty, ambiguity, and stress to the organization (March and Olsen 1976). In this study, we focus on such technology-related and accidenttriggered crises (Perrow 1984). We differentiate a crisis from a disaster, defining a crisis as a critical and stressful condition that can be triggered by human errors or technology malfunctions internally, or extreme and surprise factors externally (Hermann 1963), while defining a disaster as a severe negative consequence resulting from the failure to properly handle a crisis.

Much of the previous research on technology-based crises has focused on avoidance. The basic premise was that through "better technology" or "better training," an organization should be able to avoid crises (Dunbar and Stumpf 1989, Green 1989). However, as Perrow (1984) and Rochlin (1991) noted, crises are essentially bound to happen, especially in large and complex systems. Reason (1998) further suggested that avoidance is not only impossible in theory, but has been unsuccessful in reality due to the necessity of human involvement. At the heart of the issue, as noted by March and Olsen (1976), is the fact that organizations are composed of boundedly rational individuals. Organizational decisions, which underlie all organizational activities, depend on how individuals in the organization gather, process, and communicate task-related information (Perrow 1986, Scott 1987, Simon 1947). Factors that inhibit information processing - such as missing information or personnel turnover-may result in less accurate organizational decisions and thus reduce firm performance. Poor decision quality, particularly in a crisis situation, can have devastating consequences.

As widely documented by other scholars (Baligh et al. 1990, Mackenzie 1978, Scott 1987), we believe that the organizational design and the task environment interact to affect organizational performance in crisis situations (Lin 2000a, Pearson and Mitroff 1993). Indeed, recent research on adaptive organizations suggests that design and expertise work synergistically to affect performance, particularly in nonroutine settings (Hollenbeck et al. 1995, Levinthal and Warglien 1999). Researchers with a complexity theory perspective have started to address crisis management by exploring the role of past organizational designs at the edge of chaos (Brown and
Eisenhardt 1998). Others have suggested that organizations can buffer the impact of a crisis and make fewer erroneous decisions through loose coupling (Thompson 1967, Weick 1969) or structural redundancy (La Porte and Consolini 1991, Roberts 1990), which has further led to the growing interest in high-reliability organizations (Bigley and Roberts 2001, Roberts 1990). In contrast, Hermann (1963) and Staw et al. (1981) pointed to the value of highly centralized but not necessarily redundant structures in managing a crisis. Shaw (1981), however, also noted that decentralized organizations can respond quickly to complex tasks and therefore should perform better during crises. In addition, the allocation of and access to resources have been emphasized as vital to organizational survival, especially in crises situations, during which resources become scarce (Pfeffer and Salancik 1978).

The extensive and often contradictory suggestions in the literature have pointed out the need for a coherent framework of organizational performance to dealing with crises. An examination into whether there may exist a class of designs that-while not always yielding the absolute best performance under all conditions are nevertheless good enough and robust in the face of crises-has also become critical.

\section{A Neo-Information Processing Perspective}

We are interested in understanding the relationship between organizational design and performance, particularly in crisis situations that makes it critical for the organization to make timely and correct decisions in order to minimize the risk of a crisis developing into a disaster. We take a neo-information processing approach and characterize organizations as open systems consisting of cognitively restricted, socially situated, and task-oriented actors who interact with other members of the organization and are affected by ambiguity and past experience (Carley and Prietula 1994, Lin and Carley 2003). Organizational decisions result from the collective and integrative actions of all the actors as they work, gather information, learn, communicate, and make individual decisions in a task knowledge space (Carley and Hill 2001). Due to their bounded cognitive ability, organizational members often have to interpret and construct the environment based on prior interactions, partial information, and past experience (Daft and Weick 1984). Previous research has indicated that organizational performance is affected by myriad factors including, though probably not limited to, the lines of communication and command connecting these individuals (organizational authority structure and the degree of centralization) (e.g., Mackenzie 1978), the resources and information to which the individuals have access (Pfeffer and Salancik 1978), the nature of the task faced by the individuals (Baligh et al. 1990), and the type and severity of the crisis under which the individuals operate (Perrow 
1984). Organizations with designs that facilitate information processing and accurate decision making should, in theory, exhibit higher performance when faced with crises as well as in other situations, though systematic explorations are lacking (Perrow 1994).

\section{Method: A Matched Analysis}

For this study, we use a somewhat novel approach by conducting a matched analysis of multiple cases for theoretical insights: a combination of empirical and computational analysis (Eisenhardt 1989, March et al. 1991). We not only compare our computational model with reality, but also use it to extend our understanding beyond reality. The computational model serves as an encapsulation of organization theory and generates a series of predictions regarding how to design an organization for an effective performance in response to a crisis. The reality is a set of data concerning the relative effectiveness of 80 real organizations faced with actual crises. Using these 80 cases, we generate a matching set of 80 artificial organizations from the computational model. This allows us to closely track organizational behavior and performance and gain extended theoretical insights. By linking real-world cases with the computational model through a common set of factors, we are able to find a clearer causal relationship between each specific variable and organizational performance while holding others constant. With the incorporation of learning and nonlinear dynamic processes, we can further use the artificial organizations generated from the computational model to predict whether the performance of the real organizations would have been higher or lower if they had not been restructured or had been restructured in a different way. Using such "what if" analyses, we can begin to assess the relative value of restructuring organizational design in response to a crisis. Figure 1 shows a road map that might help us to better grasp this exploratory approach as also advocated by other scholars (Taylor and Van Every 2000).

We believe that this matched analysis approach, though still exploratory in nature, can make significant contributions to the field of organization science. It not only has allowed us to conduct cross-method validations, but also has enabled us to move beyond the limitations of pure computer simulation and enhance the theoretical rigor of the multicase approach advocated by Eisenhardt (1989). Rather than seeking degrees of freedom from a large standardized data set, our approach tests a "theory with degrees of freedom coming from the multiple implications of [the] theory" (Campbell 1975, p. 182). Such a pattern-matching process, as further described by Yin (1994, p. 106), can be achieved by "compar[ing] an empirically based pattern with a predicted one (or with several alternative predictions)," therefore strengthening the validity of the theory.
Figure 1 A Road Map for the Matched Analysis

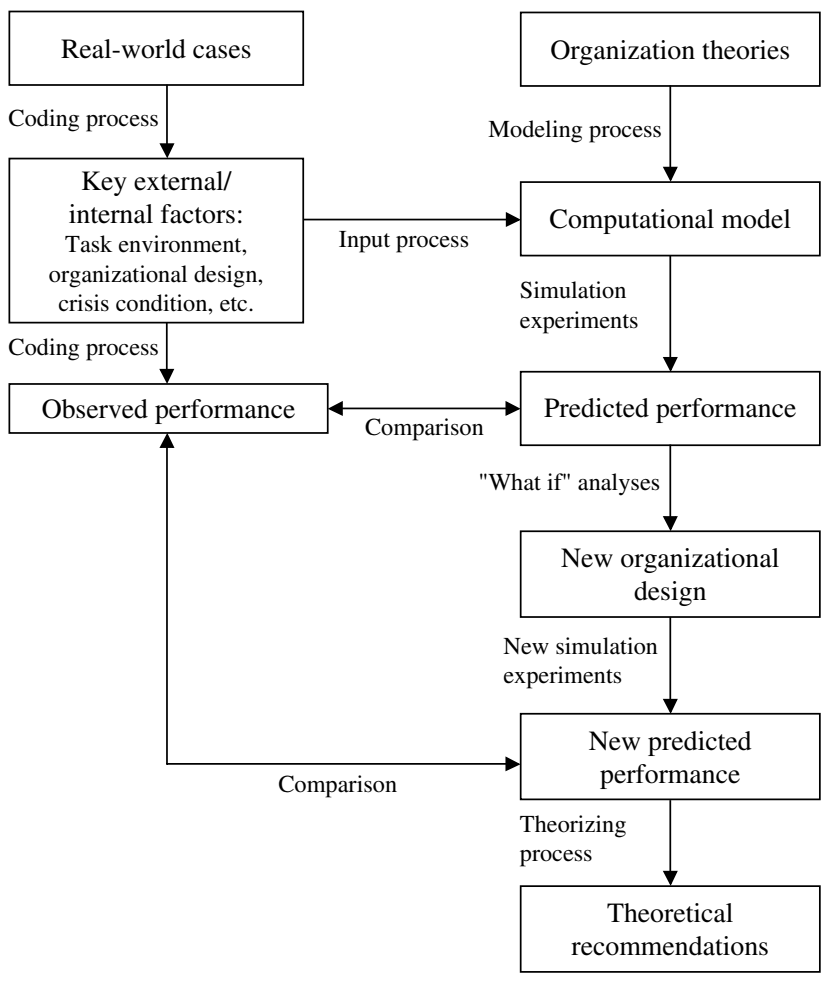

The matched analysis also allows us to compare the organizational performance of a dynamic system across different conditions (usual and crisis), and explore the evolutionary aspect of organizations (Vromen 1995). We believe these comparisons are valid for two main reasons. First, we follow the argument by Perrow (1984) that crises may become inevitable or normal as the complexity of organizational tasks increases. In other words, a crisis may not be totally novel to an organization but may have organizational design traps (Brown and Eisenhardt 1998). Research on normal accidents shows that organizations do train for these crisis situations, although a real crisis often presents more critical challenges to the organizations, both internal and external, in terms of time pressure, availability of information, and potential design malfunctions (Perrow 1984, Weick and Roberts 1993).

Second, we take the neo-information processing perspective and believe that the phenomenon of a crisis can be explored from a common set of external and internal factors. By comparing performance under crisis and usual situations, we can infer the impact of the crisis and explore the role of organizational design. Thus, we are comparing two states of a dynamic system. While this may not be the most realistic reconstruction of the reality due to real data constraints, it has the advantage of providing plausible theoretical explanations for organizational adaptations (Carley and Hill 2001, Vromen 1995). 


\section{An Overview of the Computational Model: CORP}

Researchers in the crisis management field have sometimes turned to computational models (Rolfe et al. 1998, Rosenthal and Pijnenburg 1991, Walker 1995). While these models have provided important insights into various issues of crisis management, they tend to follow the engineering tradition with the belief that the reality can be fully captured if the model is complex enough (Thompson 1994). As a result, they have frequently ignored findings from the field of organization science, and overlooked the underlying mechanisms that drive the crisis phenomenon.

For this study, we take a different approach-one based on organization theory (Cohen and Cyert 1965). We follow Simon's premise (1947, 1973), which recognizes the limit of human cognition. We strive to focus on the essence of the reality that is most relevant to the research issue. Our computational model, which we refer to as CORP (Computational ORganizational Performance framework) is based on the work by Carley and Lin $(1995,1997)$. To have a more robust match with the empirical data and to focus on the issues relevant to this study, we have aggregated some aspects of organizational design and task environment in this study. The design of the model has followed the call by Burton and Obel (1995) for a balance of relevancy, realism, and simplicity in computational models; the design has been shown to be both empirically valid and methodologically reliable (Carley 1996, Carley et al. 1998). Through virtual experiments, CORP enables us to conduct precise and consistent analyses of organizational performance under crisis situations, while we grasp key organizational features. A general algorithm is also available in the appendix.

CORP, as a multiagent network model of organizations that draws on the findings in contingency theory (Baligh et al. 1990, Scott 1987), information processing theory (Galbraith 1977, March and Simon 1958), and cognitive science (Hutchins 1991, Newell 1990), embodies the neo-information processing perspective. Like other agent-based models, CORP examines not only cognitively intelligent individual members (nodes) and their adaptive interpersonal relationships, but also organizational-level outcomes in a dynamic and controlled setting. It permits researchers to examine the emergent patterns of human interactions based on more realistic replications of basic human behaviors, and to explore the evolution of organizational change during crises (Carley and Lin 1997, Mantzavinos 2001, Siggelkow and Rivkin 2005, Vromen 1995). Through CORP, we are able to look at a fundamentally nonlinear dynamic system and compare two states of such a system where a change has occurred, thereby exploring how a single perturbation may play out in terms of change in behaviors.
CORP has three main components: task problems, individual agents, and organizational processes. They are linked in a distributed decision-making setting in which individuals must coordinate when facing a series of multicomponent task problems.

Task Problems. In CORP, the organization faces a sequence of radar-detection problems, as documented in other studies (Hollenbeck et al. 1995) and reflected in real-world cases (Roberts and Dotterway 1995). Each problem is defined as a single aircraft moving through the airspace. Each aircraft has nine indicators: speed, direction, range, altitude, angle, corridor status, identification, size, and radar emission type. Each indicator can take on a certain range of values and may be interpreted by the analyst in charge of the respective radar equipment as fitting into one of the three categories (1, 2, or 3), which can be assigned different meanings based on the research purpose. For example, in the radar detection setting, if the radar emission type's value is 0 (civilian), it is interpreted as having a Type 1, or friendly, nature. If the value is 2 (military), it is then interpreted as having a Type 3 , or hostile, nature. However, each individual indicator may not reflect the true state of the aircraft as a whole, which is defined in the task environment (appendix) and is not previously known to the organization.

We chose this task for three reasons: First, it is a real-world problem that has been widely examined in military and civilian (e.g., air-traffic control) contexts (Hollenbeck et al. 1995, Roberts and Dotterway 1995). Although we think of this task as radar control, in reality it is a ternary choice task. Any task where the agents can choose between three options has features in common with this task (March and Olsen 1976). Second, because the true outcome of the decision can be known later, not only can accuracy of performance be measured, but feedback can also be provided for learning to take place. Third, the task is ideal for a distributed environment because it is sufficiently complex that it requires multiple agents working on different aspects of the task.

Individual Agents. The building blocks of CORP are agents, which represent individual members of the organization. Each agent can carry out some basic functions, including reading information from other sources-information from the task problem or recommendations of other agents, processing information according to a specific procedure and memory, passing out information, or updating memory from feedback (Carley and Lin 1997).

Although such individuals are highly abstract, they embody the decision-making essence of a boundedlyrational human being (March and Simon 1958). With the assumption of organizations as interpretive systems (Daft and Weick 1984), each individual follows the satisficing approach with the most convenient, familiar, and 
predisposed solutions, obtained through existing organizational procedures or heuristic shortcuts based on prior experience. As in the real world, agents go through training in which consequences of their decisions can be taught, therefore enabling them to form specific judgments and to assign certain weights regarding the nature of the information they receive. Of course, such interpretation process can lead to biased judgment due to members' bounded rationality and structural constraints (Carley and Lin 1997, Lant and Mezias 1992), as will be illustrated in the Vincennes incident below.

Organizational Processes. The organizational level decision to classify the nature of the emerging task problem is the result of collective and integrative actions of all the individuals in a holistic rather than a simple additive fashion. The organization is characterized by the lines of communication (organizational structure), and by who has access to what task components (resource access structure). Each organization operates under different external situations (task environments that can include different types of problems) and internal conditions (standard or substandard operating conditions).

Such a model can find its counterpart in real-world cases. For example, a review of the 1988 Vincennes incident shows that the warship generally faced a hostile external environment. On the day of the incident, the warship faced a critical problem when an incoming aircraft was spotted while it was engaged in a surface gunfight with several Iranian armed boats. The crisis was triggered due to the misinterpretation of a piece of information by one of the radar operators (analysts) regarding whether the aircraft was civilian or military (U.S. Congress 1988). Due to the time pressure and the prevalent hierarchy structure on the warship, there was not sufficient cross-checking (Watson et al. 1988). This was coupled with the fact that the training of the personnel was biased toward superpower confrontations and protection of the warship (Duffy et al. 1988). Although this is a stylized case, reflecting more of the organization's formal structure and process, it again shows how an organization's decision may be the result of its members' experiences, interactions, and perceptions. Similarly, in the computational model we can build an artificial organization with a hierarchy command structure, and a segregated resource access structure (each operator in charge of one decomposed task component). Agents of the artificial organization go through operational training by facing simulated problems of different natures, with bias toward the correct assessment of one type of problems, say Type 3 (hostile). The decision-making process starts with the base-level analysts scanning the environment and reporting their judgment on each of the indicators for which their equipment is responsible; in the Vincennes incident, their judgment was hampered by incorrect information and misinterpretation. The supervising officer then summarizes and reports to the captain for his decision. In the case of Vincennes, the final organizational decision was made by the captain to shoot down the incoming aircraft. That later turned out to be an incorrect decision.

\section{An Overview of the Empirical Data: Eighty Real-World Crisis Cases}

Using archival sources, information was collected on the organizational design characteristics, external and internal factors, and performance of 80 organizations faced with technological crises. These technological crises create a critical and stressful situation, typically caused by a critical external environment or a specialized lesscommon task, or both, coupled with substandard operating conditions, to which the organization must respond rapidly and accurately to mitigate adverse consequences or disasters (Lagadec 1981). The cases were drawn from various industries. For each crisis, we focused on the main organization whose behavior and decision directly affected the cause and outcome of the crisis (Table 1).

The collected data describe the value of each relevant variable in usual situations (prior to crises) and during crises. We did not examine organizational behavior in the aftermath or the cleanup stage of the crisis. The data on the 80 organizations were gathered using a variety of independent sources including journal articles, books, and news media. For each of the real organizations, we did not capture detailed data on the specific behavior, access to resources, and position of each individual in the organizations in the crisis response unit. Instead, we collected general data on ways in which the directly responsible organization is designed. We identified a crisis period as the time from the beginning of the incident to the end of the incident. The beginning of the incident occurs when the first signal of the incident is detected by the organization. The end of the incident occurs when the incident is under control and the possibility of escalation has ended. ${ }^{1}$

\section{Matched Measures}

We now provide more detailed descriptions of main measures from both the simulation model and the empirical data. (See Table 2 for an illustration of matched measures using a real crisis case.)

Task Environment. We define the collection of task problems as the task environment, which provides external sources of information to the organization (Aldrich 1979, Burton and Obel 2004, Dill 1958, Mackenzie 1978). Task environments vary on a number of dimensions, with focus often being on complexity and uncertainty (Anderson and Tushman 2001) that are fundamentally about the interrelationships among and diversity of the components of task environments (Aldrich 1979, Hannan and Freeman 1977, Roberts 1990, Simon 1962, ZeyFerrell 1979). 
Table 1 A List of Crisis Cases

\begin{tabular}{|c|c|c|c|c|}
\hline Number & Case description with focal organization italicized & Industry & Year & Main sources \\
\hline 1. & Leakage of toxic gas by Union Carbide at Bhopal, India & Chemical & 1984 & $2,5,28,29,30,66,70$ \\
\hline 2. & Explosion of nonconfined vapor by Nypro at Flixborough, UK & Chemical & 1974 & $1,2,63,70$ \\
\hline 3. & $\begin{array}{l}\text { Aerosol of solid toxic product by Industrie Chimiche Meda Societa Anoima } \\
\text { at Sevesco, Italy }\end{array}$ & Chemical & 1976 & $1,2,70$ \\
\hline 4. & Explosion of ammonia nitrite by Amoco at the port of Texas City, Texas & Chemical & 1947 & $1,2,87,88$ \\
\hline 5. & Explosion of nonconfined gas cloud at Feyzin Oil Refinery, France & Chemical & 1966 & 1,64 \\
\hline 6. & $\begin{array}{l}\text { The mismanagement of toxic waste by the City Government of } \\
\text { Niagara Falls at Love Canal, New York }\end{array}$ & Chemical & 1978 & $1,2,38,39,40,41,70$ \\
\hline 7. & Explosion of chemicals at Chemstar Chemicals, UK & Chemical & 1981 & 11,65 \\
\hline 8. & Leakage of white sulfuric acid fume at Staveley Chemicals, UK & Chemical & 1982 & 11,62 \\
\hline 9. & Explosion of ammonium nitrate at Cory Chemicals' warehouse, UK & Chemical & 1982 & 11,75 \\
\hline 10. & Explosion of chemicals at Dow Chemicals, UK & Chemical & 1977 & 11,127 \\
\hline 11. & Explosion of chemicals at Laporte Industries, UK & Chemical & 1975 & 11,128 \\
\hline 12. & Explosion at Manro Products, UK & Chemical & 1982 & 11,78 \\
\hline 13. & Release of ethyl acrylate by Sybron Chemicals, New Jersey & Chemical & 1988 & 13,76 \\
\hline 14. & Pollution of chemical products by Manville Corporation, U.S. & Chemical & 1978 & $15,90,91$ \\
\hline 15. & Fire explosion of a huge heater at a Louisiana power plant & Chemical & 1974 & 2,120 \\
\hline 16. & $\begin{array}{l}\text { Sinking of Lash Atlantico due to collision with Hellenic Carrier at } \\
\text { Kitty Hawk, U.S. }\end{array}$ & Navigation & 1981 & 2,129 \\
\hline 17. & Sinking of S.S. Transhuron, Arabian Sea & Navigation & 1974 & 2,68 \\
\hline 18. & Sinking of Whit Star Line's Titanic, Atlantic Ocean & Navigation & 1912 & $2,70,89$ \\
\hline 19. & Collision with a bridge by Summit Venture, U.S. & Navigation & 1971 & $2,61,83$ \\
\hline 20. & Sinking of the cargo ship U.S. Steel Vendor, Pacific Ocean & Navigation & 1971 & 2,69 \\
\hline 21. & Collision by Cuyahoga with Santa Cruz II, in Chesapeake Bay, U.S. & Navigation & 1978 & $1,2,84$ \\
\hline 22. & Fire of the tanker General Slocum, in New York & Navigation & 1904 & $2,79,80,81,82$ \\
\hline 23. & Collision by Keytrader with Baune in the Mississippi river, Mississippi & Navigation & 1974 & $2,71,72$ \\
\hline 24. & Collision by Pisces with Trade Master in the Mississippi river, Mississippi & Navigation & 1982 & 2,130 \\
\hline 25. & Sinking of the Squalus of the U.S. Navy, in New Hampshire & Navigation & 1939 & 51,70 \\
\hline 26. & Sinking of Thetis at Liverpool Bay, UK & Navigation & 1939 & 52,70 \\
\hline 27. & Sinking of Threasher of the U.S. Navy, Atlantic Ocean & Navigation & 1963 & $53,54,70$ \\
\hline 28. & Crash of DC-10 due to mismanagement by Air New Zealand, New Zealand & Aviation & 1979 & $1,2,85,86$ \\
\hline 29. & A near crash of DC-8 due to mismanagement of Capital Airways, New York & Aviation & 1982 & 1,2 \\
\hline 30. & $\begin{array}{l}\text { Crash of DC-10 of due to mismanagement by American Airlines, Chicago, } \\
\text { Illinois }\end{array}$ & Aviation & 1979 & $1,2,70$ \\
\hline 31. & $\begin{array}{l}\text { Downing of KAL } 007 \text { due to mismanagement by Korean Airlines, in USSR } \\
\text { and South Korea }\end{array}$ & Aviation & 1983 & $3,74,77$ \\
\hline 32. & $\begin{array}{l}\text { Crash of DC-10 of Turkish Airlines at Ermenonville, Turkey, due to misoperation } \\
\text { by McDonnell Douglas }\end{array}$ & Aviation & 1974 & $1,47,70$ \\
\hline 33. & $\begin{array}{l}\text { Crash of United } 232 \text { at Sioux City, U.S. due to mismanagement of } \\
\text { United Airlines }\end{array}$ & Aviation & 1989 & $12,47,70$ \\
\hline 34. & Crash of the R-101 in France, due to mismanagement of British Air Force & Aviation & 1930 & $1,47,48$ \\
\hline 35. & $\begin{array}{l}\text { Collision of airplanes at John Wayne Orange County Airport of Orange Berets, } \\
\text { Los Angeles, California }\end{array}$ & Aviation & 1981 & 2,131 \\
\hline 36. & Disappearance of the Dixumde of French Aeronautics, France & & 1923 & 1,48 \\
\hline 37. & British Overseas Airways Corporation (BOAC) comet crash, UK & Aviation & 1954 & 48,70 \\
\hline 38. & Fire on a French Railway train at Couronnes, Paris, France & Rail & 1903 & 1,132 \\
\hline 39. & Crash of a French Railway train at Lagny Pomponne, Paris, France & Rail & 1933 & 1,133 \\
\hline 40. & British Railway train accident at Hixon, UK & Rail & 1968 & $1,48,50$ \\
\hline 41. & Explosion of a Canadian Pacific Railway train in Toronto, Canada & Rail & 1979 & 1,9 \\
\hline 42. & British Railway accident at Purley, UK & $\mathrm{Ra}$ & 1989 & $50,92,93$ \\
\hline 43. & British Railway accident at Newton, UK & Rail & 1991 & 50,94 \\
\hline 44. & Ford Motor Company's Pinto rear-impact defect, U.S. & Automobile & $1971-76$ & $70,107,108$ \\
\hline 45. & Firestone Tire and Rubber Company's Firestone 500 tire failure, U.S. & Automobile & $1972-78$ & $70,109,110$ \\
\hline 46. & Audi of America's Audi 5000 sudden acceleration incident, U.S. & Automobile & 1978-86 & $70,111,112,113$ \\
\hline 47. & Leakage of oil by Ashland Oil Inc. at Pittsburgh, Pennsylvania & Oil & 1988 & $10,43,44$ \\
\hline 48. & Leakage of oil by the Amoco Company's Cadiz at Nordfinistere, UK & Oil & 1978 & 1,45 \\
\hline 49. & Leaking of oil by Exxon's Valdez, Alaska & Oil & 1989 & $25,26,67,70$ \\
\hline 50. & $\begin{array}{l}\text { Oil spill from the Ixtoc oil well of Mexican National Well Operators Company, } \\
\text { Gulf of Mexico }\end{array}$ & Oil & 1979 & 1,125 \\
\hline 51. & Explosion of nuclear plant at Chernobyl Nuclear Power Plant, USSR & Nuclear & 1986 & $6,32,35$ \\
\hline 52. & $\begin{array}{l}\text { Leakage of nuclear radiation at The Metropolitan Edison Company's } \\
\text { Three Mile Island, Pennsylvania }\end{array}$ & Nuclear & 1977 & $1,2,33,34,35,36,37,46$ \\
\hline 53. & Nuclear accident by Tokaimura Power Station at Tokai, Japan & Nuclear & 1999 & $49,95,96,97$ \\
\hline 54. & Explosion at Kyshtym Power Plant in Sverdlovsk, USSR & Nuclear & 1957 & 55,70 \\
\hline
\end{tabular}


Table 1 (cont'd.)

\begin{tabular}{|c|c|c|c|c|}
\hline Number & Case description with focal organization italicized & Industry & Year & Main sources \\
\hline 55. & Fire at Windscale Nuclear Reactor Complex, UK & Nuclear & 1957 & 56,70 \\
\hline 56. & $\begin{array}{l}\text { Explosion of U.S. National Reactor Testing Station's SL-I } \\
\text { experimental reactor core, Idaho }\end{array}$ & Nuclear & 1961 & 57,70 \\
\hline 57. & Fire at Brown's Ferry Power Plant, Alabama & Nuclear & 1975 & 58,70 \\
\hline 58. & Explosion of space shuttle Challenger of NASA, U.S. & Space & 1986 & $3,4,27,56$ \\
\hline 59. & Explosion of Apollo 13 of NASA, U.S. & Space & 1970 & 2,70 \\
\hline 60. & Soviet's Manned Space Program's rocket fire accident, USSR & Space & 1960 & 59,70 \\
\hline 61. & NASA's Apollo I capsule fire, Florida & Space & 1967 & $60,70,118$ \\
\hline 62. & $\begin{array}{l}\text { Soviet's Manned Space Program's Soyuz I reentry } \\
\text { crash at Orenburg, USSR }\end{array}$ & Space & 1967 & 70,119 \\
\hline 63. & Fire at Douglas Corporation in Summerland, UK & Construction & 1973 & 1,8 \\
\hline 64. & $\begin{array}{l}\text { Collapse of the Grand Teton dam, managed by U.S. } \\
\text { Bureau of Reclamation, U.S. }\end{array}$ & Construction & 1976 & 2,49 \\
\hline 65. & Fire at Joelma Tower in São Paulo, Brazil & Construction & 1974 & 1,126 \\
\hline 66. & Roof collapse at Hartford Civic Center Coliseum, U.S. & Construction & 1978 & $70,98,99$ \\
\hline 67. & Fire at MGM Grand Inc.'s MGM Hotel, U.S. & Construction & 1980 & $70,100,101$ \\
\hline 68. & $\begin{array}{l}\text { Univel of Cocoal Beach's condominium } \\
\text { collapse at Harbor Cay, U.S. }\end{array}$ & Construction & 1981 & $70,102,103$ \\
\hline 69. & $\begin{array}{l}\text { Walkway collapse at Hyatt Hotels Corp.'s } \\
\text { Hyatt Regency Hotel, U.S. }\end{array}$ & Construction & 1981 & 70,104 \\
\hline 70. & $\begin{array}{l}\text { Texstar Construction Corporation's L'Ambiance Plaza } \\
\text { collapse in Connecticut }\end{array}$ & Construction & 1987 & $70,105,106$ \\
\hline 71. & The Societa Adriatica di Electricitta's Vaiont dam disaster, Italy & Construction & 1963 & $2,49,70$ \\
\hline 72. & $\begin{array}{l}\text { Los Angeles Bureau of Water Works and Supply's dam } \\
\text { failure at St. Francis, U.S. }\end{array}$ & Construction & 1928 & 49,70 \\
\hline 73. & $\begin{array}{l}\text { Explosion of mine managed by Courrieres Mining Company at } \\
\text { Courrieres, France }\end{array}$ & Mining & 1906 & 1,124 \\
\hline 74. & $\begin{array}{l}\text { Slide at Turtle Mountain managed by Canadian-American } \\
\text { Coal and Coke Company, Canada }\end{array}$ & Mining & 1903 & $49,114,115,116,117$ \\
\hline 75. & $\begin{array}{l}\text { Sliding of colliery tip from a mountain managed by } \\
\text { National Coal Board in Aberfan, UK }\end{array}$ & Mining & 1966 & 1,8 \\
\hline 76. & Diamond Crystal Salt Co.'s mining accident at Louisiana & Mining & 1980 & 2,123 \\
\hline 77. & $\begin{array}{l}\text { Agriculture disaster at Ethiopia during the regime of the } \\
\text { Ethiopian Deruge Government }\end{array}$ & Agriculture & 1984 & 9,42 \\
\hline 78. & $\begin{array}{l}\text { Communication outage at Illinois Bell Telephone Company's } \\
\text { Hinsdale switching center, Chicago, Illinois }\end{array}$ & Communication & 1988 & 14,31 \\
\hline 79. & Shooting down of civilian plane by USS Vincennes, Persian Gulf & Military & 1988 & $7,16,17,18,19,20,21,22,23,24,121$ \\
\hline 80. & $\begin{array}{l}\text { Riots during the final of } 1985 \text { European Football Cup } \\
\text { tournament organized by Belgian National Soccer Union } \\
\text { at Heysel Stadium, Brussels, Belgium }\end{array}$ & Entertainment & 1985 & 9,122 \\
\hline
\end{tabular}

Main sources. Available on request.

For this study, we categorize task environments as simple or complex (Table 2). A simple task environment is both decomposable, in which the components of the task faced by the organization can be processed independently, and concentrated, in which most problems faced by the organization are of the same type. In contrast, a complex task environment is either nondecomposable, in which the components of the task faced by the organization are dependent on each other to be processed; or dispersed, in which the organization faces problems of differing natures with no particular type of problems dominating (Aldrich 1979, Hannan and Freeman 1977, Roberts 1990).

In the real world, the accuracy of a decision can be judged only by postevent effects, or it is simply unknown. In this study, we utilize the advantage of computational modeling and build the true state of each problem in each task environment based on an independent formula unknown to the artificial organization beforehand (see appendix). With this mechanism, we have the baseline against which an organization's decision regarding each problem can be compared, and organizational performance can be measured.

\section{Organizational Form}

Organizational form can be characterized in terms of organizational authority structure and resource access structure. We focus on these factors because they have previously been shown to epitomize particular types of behavior and to correspond to forms observable in realworld organizations. They have also captured attention in the literature (Burton and Obel 2004, Lin and Carley 2003). These structures are examined because they represent typical, though abstract, versions of real orga- 
Table 2 Matched Measures of Simulation Model and Empirical Data

\begin{tabular}{|c|c|c|}
\hline Main measures & $\begin{array}{c}\text { Simulation model } \\
\text { CORP }\end{array}$ & $\begin{array}{c}\text { Empirical data } \\
\text { An example of a chemical crisis "Flixborough" in } 1974 \\
(\text { ID }=2 \text {; Sources: } 1,2,63,70)\end{array}$ \\
\hline $\begin{array}{l}\text { TSK } \\
\text { Task environment }\end{array}$ & $\begin{array}{l}\text { TSK }=2 \\
1=\text { Simple. Concentrated and } \\
\text { decomposable tasks. } \\
2=\text { Complex. Others. }\end{array}$ & $\begin{array}{l}\text { TSK }=2 \\
\text { These items refer to the characteristics of the task encountered } \\
\text { by the focal organization. Task characteristics can be } \\
\text { measured by the interdependence and concentration of the } \\
\text { task components. } \\
1 \text { = Simple. The components of the task can be processed } \\
\text { independently and most of the problems are of the same type. } \\
2 \text { = Complex. The components of the task are closely } \\
\text { dependent on each other and problems of different natures } \\
\text { can occur frequently. } \\
\text { "(The chemical plant) is quite tightly coupled, and has many } \\
\text { complexly interactive components" (2, p. 101). "Clearly (the } \\
\text { chemical industry) is not a disastrous industry for employees. } \\
\text { The low incidence of work injuries and fatalities does not mean, } \\
\text { however, that there are no plant accidents" (2, p. 104). }\end{array}$ \\
\hline $\begin{array}{l}\text { UOS } \\
\text { Usual organizational } \\
\text { form }\end{array}$ & $\begin{array}{l}\text { UOS }=1 \\
\begin{array}{l}1=\text { Simple. UST } \leq 3 \text { and UAC } \leq 1 \\
2=\text { Complex. All others. } \\
\text { UST: Usual organizational structure. } \\
1=\text { team } \mathrm{w} / \text { voting, } 2=\text { team } \mathrm{w} / \text { manager, } \\
3=\text { hierarchy, } 4=\text { matrix. } \\
\text { UAC: Usual resource access structure. } \\
1=\text { segregated, } 2=\text { overlapped, } \\
3=\text { blocked, } 4=\text { distributed. }\end{array}\end{array}$ & $\begin{array}{l}\text { UOS }=1 \\
1=\text { Simple form. Simple and nonoverlapping communication } \\
\text { channels such as team and simple hierarchy with segregated } \\
\text { resource access schemes. } \\
2 \text { = Complex form. Complex and overlapping communication } \\
\text { channels with redundant resource access schemes. } \\
\text { Communication at Flixborough was predominantly vertical, } \\
\text { with no overlap in the chains of command in the structure. } \\
\text { Daily operations were carried out in a segregated form. } \\
\text { Each member was responsible for his/her own engineering, } \\
\text { operational or maintenance functions }(1, \mathrm{p} .27) .\end{array}$ \\
\hline $\begin{array}{l}\text { COS } \\
\text { During crisis } \\
\text { organizational } \\
\text { form }\end{array}$ & $\begin{array}{l}\text { COS }=2 \\
1=\text { Simple. DST } \leq 3 \text { and } \mathrm{DAC} \leq 1 \\
2=\text { Complex. All others. } \\
\text { CST: During crisis organizational structure. } \\
\text { CAC: During crisis resource access } \\
\text { structure. }\end{array}$ & $\begin{array}{l}\text { COS }=2 \\
1=\text { Simple form. Simple and nonoverlapping communication } \\
\text { channels such as team and simple hierarchy with segregated } \\
\text { resource access schemes. } \\
2 \text { = Complex form. Complex and overlapping communication chan- } \\
\text { nels with redundant resource access schemes. } \\
\text { While Flixborough maintained its hierarchical structure during } \\
\text { crisis, there was overlap in resource access structure. At the } \\
\text { time of the incident, there was reorganization of process going } \\
\text { on in the company. For example, just prior to the incident, "the } \\
\text { duties of the maintenance engineer, especially coordination } \\
\text { were given provisionally to a subordinate" (1, p. 26). }\end{array}$ \\
\hline $\begin{array}{l}\text { CMT } \\
\text { Type of } \\
\text { substandard } \\
\text { condition during } \\
\text { crisis }\end{array}$ & $\begin{array}{l}\mathrm{CMT}=3 \\
1=\text { Information uncertainty-based } \\
\text { substandard conditions (missing } \\
\text { information, incorrect information) } \\
2=\text { Agent malfunction-based uncertainties } \\
\text { (agent unavailability, communication } \\
\text { breakdown, agent turnover) } \\
3=\text { Joint substandard conditions (using } \\
\text { aggregations) }\end{array}$ & $\begin{array}{l}\mathrm{CMT}=3 \\
1=\text { Information uncertainty-based substandard conditions. One } \\
\text { or more of pieces of information are not available or complete, } \\
\text { or are incorrect when needed to make decisions that were } \\
\text { related to the organizational operations. } \\
2=\text { Agent malfunction-based uncertainties. One or more } \\
\text { members of the organization are not at post, or one or more } \\
\text { normal communication channels are down, or one or more fully } \\
\text { trained agents left when needed to make decisions that are } \\
\text { related to the organizational operations. } \\
3=\text { Joint substandard conditions. When the substandard } \\
\text { condition is caused by a combination of both information } \\
\text { uncertainty and agent malfunction. } \\
\text { Information uncertainty (missing information): "They neglected to } \\
\text { consider how the pipe would behave under continual high } \\
\text { temperature and pressure" (70, p. 392). } \\
\text { Agent malfunction (unavailability): "... There was no qualified } \\
\text { mechanical engineer with a status of sufficient authority to deal } \\
\text { with complex or novel engineering problems or to demand that } \\
\text { necessary measures were taken" ( } 1 \text {, p. 32). } \\
\text { Agent malfunction (turnover): "At the beginning of } 1974 \text { the } \\
\text { maintenance engineer left the factory for personal reasons, } \\
\text { and by June 1974 the company had not yet found a } \\
\text { replacement" ( } 1 \text {, p. } 26 \text { ). }\end{array}$ \\
\hline
\end{tabular}


Table 2 (cont'd.)

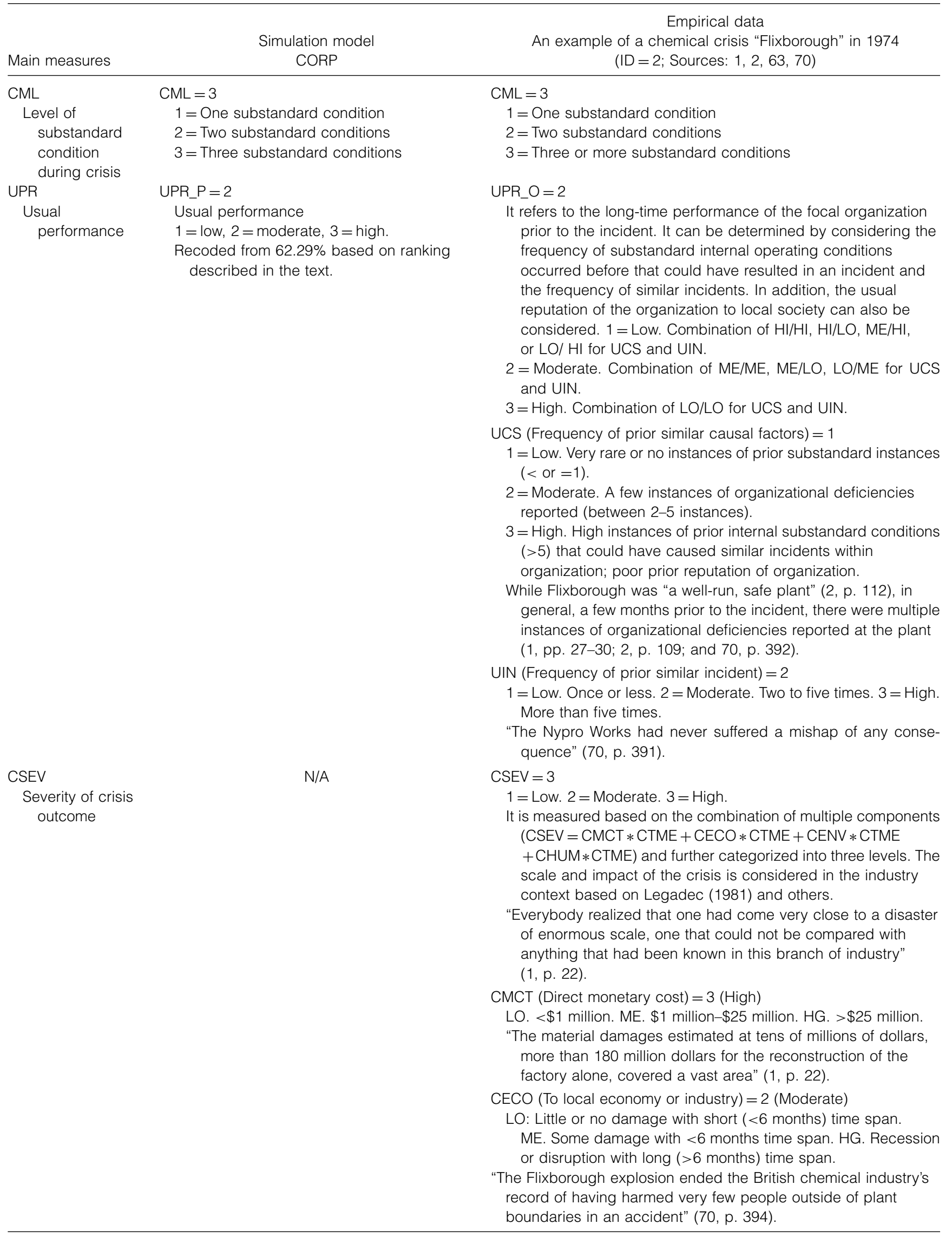


Table 2 (cont'd.)

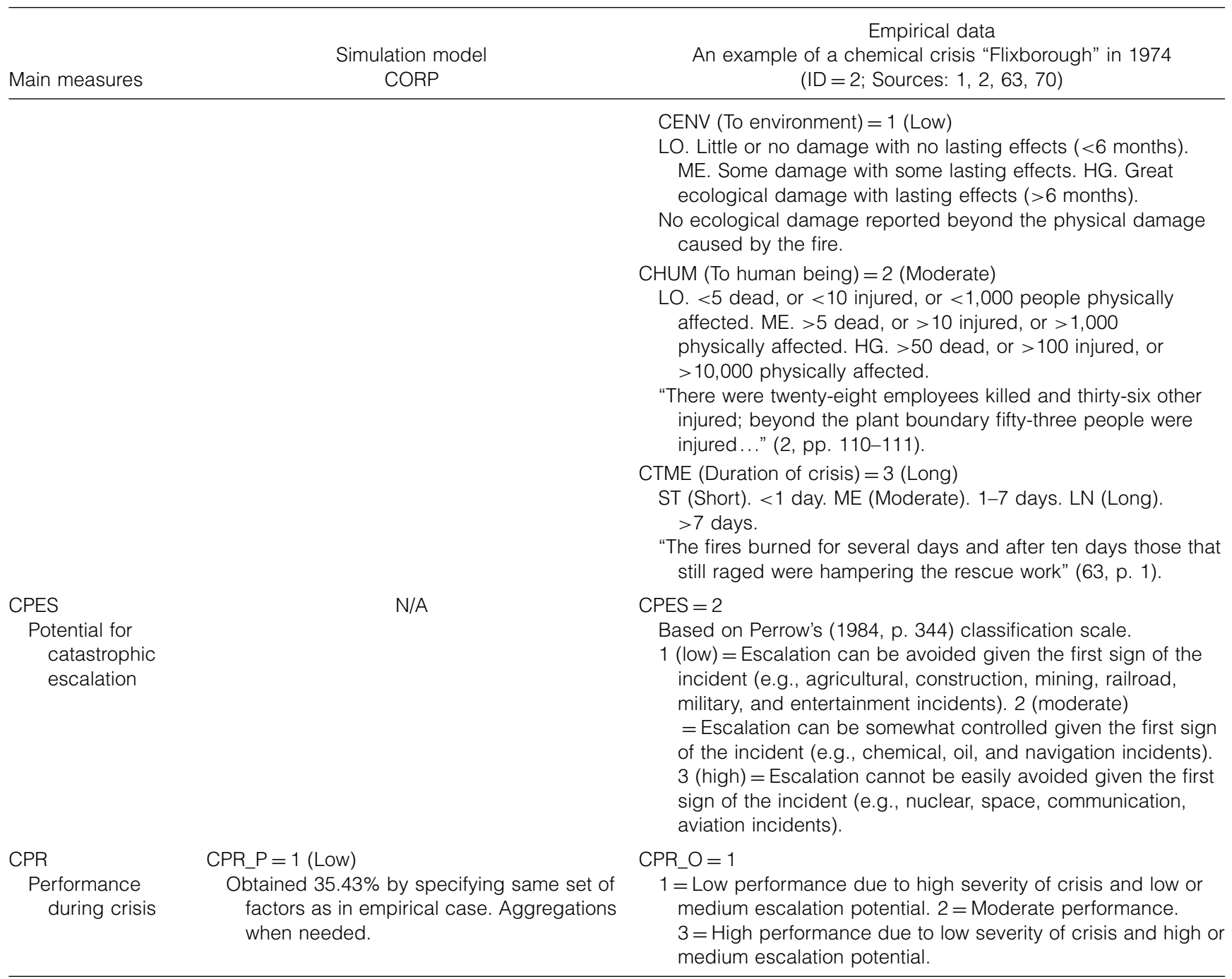

Sources. [1] Lagadec (1981); [2] Perrow (1984); [63] Health \& Safety Executive (2001); [70] Schlager and Schlager (1994).

nizations (Courtright et al. 1989, Miles and Creed 1995). Each type of structure has been analyzed by various research traditions, but the structural impact on performance has rarely been contrasted systematically, with perhaps the exception of Burton and Obel (2004), Carley and Lin (1995, 1997), and Lin and Carley (1997).

For this study, we categorize organizational form as simple or complex (Table 2). A simple organizational form consists of nonoverlapping communication channels such as a team or a simple hierarchy with a segregated resource access structure. In contrast, a complex form is composed of complex and overlapping communication channels such as a matrix structure or other structure, but with a nonsegregated resource access structure (Carley and Lin 1995, Cohen et al. 1972, Davis and Lawrence 1977, Mackenzie 1978).

\section{Modeling Crisis Conditions}

Crises are typically caused by both external and internal stress factors, and have the potential to result in catastrophic consequences if wrong decisions are made (Pearson and Mitroff 1993, Perrow 1984, Staw et al. 1981).

Internal Stress: Substandard Operating Conditions. Organizations do not always operate as ideally designed, thus causing operational malfunctioning. It is important to consider operating conditions because they can cause ambiguities and uncertainties that may subsequently degrade organizational performance (Carley and Lin 1997, March and Olsen 1976). In this study, such operating conditions are defined as a substandard state of the organization with respect to information uncertainty (such as missing information and incorrect information) or agent malfunction (such as agent unavailability, communication channel breakdown, and agent turnover) or both (Table 2).

Within CORP, we can also examine varying degrees of severity of substandard operating conditions. For each organization, the location of a substandard condition is 
chosen randomly for each problem. When there are joint substandard conditions, CORP will use the aggregated result because it only allows one type of substandard condition to occur in each simulation experiment.

External Stress: Extreme or Critical Situations. Organizations sometimes face extreme or nonroutine problems that could have undesired consequences if they are mishandled (Carley and Lin 1995, Perrow 1984, Staw et al. 1981). In the real world, the presence of such external stress may be known after the crisis is reported. In CORP, we define an external stress situation as one during which the organization faces an extreme problem, i.e., a Type 3 problem, which can be assigned a meaning of hostile for training and decision-making purposes. Our approach also contains the assumption that CORP assigns equal importance to minimizing Type 1 and Type 2 errors.

\section{Organizational Performance}

Organizational performance can be characterized in a number of ways, including accuracy and timeliness in decision making; market share; and stakeholder perceptions. Nevertheless, given that decision making is the core of organizational operations (Scott 1987), the ability of an organization to accurately understand a problem and provide an appropriate solution to it becomes critical, particularly in a crisis situation, when a misjudgment about the nature of the problem can have a great impact on organizations. In CORP, we measure organizational performance in usual and crisis conditions. For usual performance, we measure decision accuracy across all 19,683 (nine indicators with each taking three possible values, or $3^{9}$ ) possible events. For crisis performance, we measure decision accuracy across just those events defined to be critical and where there are one or more substandard conditions.

In the real world, however, while the key factors of the real organizations and their artificial counterparts from the computational model share similar characterizations, there is a discrepancy between the performance measures. For the 80 real organizations, performance cannot be measured simply as accuracy of the decision choice. This is because the true state is often unknown. Thus, we take a qualitative approach to measuring organizational performance in the empirical part.

The measurement of the usual performance mainly takes into account (a) the frequency with which substandard internal operating conditions had previously occurred in the focal organization which could have resulted in a crisis, and (b) the frequency of similar crises in the past. In addition, the usual reputation of the organization in local society is considered when available. The measurement of the crisis performance is based on the actual severity of the crisis outcome, as well as on the potential for catastrophic escalation of the crisis (Table 2).
As can be seen, there are discrepancies in the performance measures of real and artificial organizations. In capturing the performance of the artificial organizations, we took a Monte Carlo approach. The performance of each organization was estimated across a number of independent decisions (regarding a series of radar detection problems) while under a specific combination of external and internal conditions. In the real organizations, we could only measure performance on a single trial. Thus, we are using the simulated data to provide an average behavior of organizational performance under conditions similar to the one faced by the real organization.

The second, and more critical, difference is that for an artificial organization from CORP, performance is measured as the percentage of correct decisions, which varies from $0 \%$ to $100 \%$; while for a real organization, performance is coded as low, moderate, or high. To facilitate performance comparisons between real and artificial organizations, we recategorized the performance of artificial organizations into a three-point scale: low, moderate, and high. We first located the number of low, moderate, and high performers in the 80 real-world cases, based on observed crisis performance. There are 40 low, 22 moderate, and 18 high performers. Second, we rankordered the predicted crisis performance of the matching 80 artificial organizations from the lowest to the highest. Third, we recategorized the performance of the lowest 40 artificial organizations as low, the next 22 as moderate, and the highest 18 as high. The same strategy was used for usual performance, for which there are 31 low, 39 moderate, and 10 high performers in the real cases. This transformation, compared with other methods using arbitrary cutoff values, requires less subjective judgment and minimizes potential outliers, therefore enhancing robustness and validity for the matched analysis.

Although the methods used to access real data performance and artificial data performance are not identical, both methods provide feasible estimates of overall organizational performance on decision tasks. By converting performance measures into a three-point scale, we are treating both approaches in a sufficiently coarse grain that makes vagaries due to the specific decision task less relevant. We note that the approach we have used is particularly relevant for usual performance and crisis performance where the performance of the real organization is often a qualitative estimate of the overall performance that takes into account a large number (often hundreds) of individual decisions that might have happened, but that were not specifically captured by the archival sources. Based on the case studies, we can expect that the more accurate these individual decisions, the higher the overall performance. Similarly, the computational model gives an indicator of performance as a general function of accuracy. Overall performance, not specific performance, is being predicted. 
We find substantial agreement between the model and the reality. For usual performance, we see a $66.3 \%$ match between the two. Of the mismatches, most are minor with one level away (i.e., not situations when the empirical data rates high while the model predicts low). For crisis performance, we see a $56.3 \%$ match between the two. Of the mismatches, most are also minor and occur for moderate performers. These numbers show the strength of CORP for predicting the relative rank or performance. While such agreement has suggested the plausibility of the matched analysis, the ways that different organizational designs and crises may impact organizations in the computational model and the real world as well as "what if" analyses, still need more fine-grained experimental designs. Table 3 lists the descriptive statistics of the main variables and the correlation results.

\section{Summary}

Our study, according to some scholars, falls into the category of multilevel research, because it deals with not only the individual level, but also the organizational level, as well as the interactions of the two types of levels (Klein et al. 1999, Rousseau and House 1994). Those scholars suggest that multilevel research requires fundamentally different thinking than conventional research, because the causal relationship between the microlevel behavior and the macrolevel organizational outcome may no longer follow conventional statistical analogy (Klein et al. 1999, Rousseau and House 1994).

Although our emphasis is not on the degree of freedom as in conventional large-scale data analyses, whenever possible we conduct statistical analysis to see if there are significant discrepancies between each pair of predicted and observed data through the use of $t$-tests. We then dissect the pattern within each predicted and observed data set to explore if within-pattern variations exist, again through the use of $t$-tests. In some situations when the degree of freedom is too small due to the scarcity of real data, we provide a pseudostatistical comparison by identifying the sample size at which point statistical differences may be significant. However, this pseudotest is only taken when there is a good theoretical justification based on the initial pattern predicted from the computational model. This is a feasible approach for complementing case analysis, given that in CORP the performance outcome for each organization under each unique situation is actually the result of 19,683 runs. In other words, small differences from the computational model may actually carry more significance.

\section{Designing for High Performance}

The history of organizational theory has centered on organizational performance, yet the issue of what contributes to an organization's good performance, especially under crisis situations, has not been sufficiently addressed. By taking a neo-information processing perspective, we believe that there is systematicity to the underlying relationships among task environment, organizational design, and crisis, which can ultimately affect organizational performance.

\section{The Impact of Task Environment}

We begin by examining the impact of task environment on organizational performance. The literature has pro-

Table 3 Descriptive Statistics and Spearman Correlation

\begin{tabular}{llllllllllrr}
\hline Variable & $N$ & Min & Max & Mean & Std. & 2 & 3 & 4 & 5 & 6 & 7 \\
\hline 1. UPR_O & 80 & 1.00 & 3.00 & 1.74 & 0.67 & $0.49^{* *}$ & 0.09 & 0.11 & -0.14 & 0.05 & 0.08 \\
2. UPR_P & 80 & 1.00 & 3.00 & 1.74 & 0.67 & & 0.08 & 0.05 & 0.03 & 0.21 & 0.08 \\
3. CPR_O & 80 & 1.00 & 3.00 & 1.73 & 0.81 & & & $0.58^{* *}$ & -0.16 & -0.06 & -0.01 \\
4. CPR_P & 80 & 1.00 & 3.00 & 1.73 & 0.81 & & & & -0.21 & 0.06 & 0.22 \\
5. CML & 80 & 1.00 & 3.00 & 2.24 & 0.75 & & & & & -0.07 & -0.06 \\
6. UCM & 80 & 1.00 & 2.00 & 1.46 & 0.50 & & & & & & $0.35^{* *}$ \\
7. CCM & 80 & 1.00 & 2.00 & 1.49 & 0.50 & & & & & & \\
Categorical variables & & & & & & & & & & & \\
8. TASK & 80 & 1.00 & 2.00 & 1.36 & 0.48 & & & & & & \\
9. UOS & 80 & 1.00 & 2.00 & 1.35 & 0.48 & & & & & & \\
10. CMT & 80 & 1.00 & 3.00 & 2.38 & 0.88 & & & & & & \\
11. COS & 80 & 1.00 & 2.00 & 1.63 & 0.48 & & & & & & \\
12. SFT & 80 & 0.00 & 1.00 & 0.31 & 0.47 & & & & & & \\
\hline
\end{tabular}

Notes. UCM: Level of complexity match between organizational form and task environment during usual conditions, with $1=$ low, $2=$ high.

CCM: Level of complexity match between organizational form and task environment during crisis, with $1=$ low, $2=$ high.

SFT: Shift status of organizational form during crisis as compared with usual organizational form, with $0=$ no shift, $1=$ shift.

Other variable descriptions can be found in Table 2.

*Correlation is significant at the 0.05 level (two-tailed).

${ }^{* *}$ Correlation is significant at the 0.01 level (two-tailed). 
Table 4 The Effect of Task Environment on Performance

\begin{tabular}{lccccc}
\hline & \multicolumn{2}{c}{ Usual performance } & & \multicolumn{2}{c}{ Crisis performance } \\
\cline { 2 - 3 } Task environment & Prediction & Observation & & Prediction & Observation \\
\hline Simple & $1.82(51,0.68)^{\mathrm{a}}$ & $1.76(51,0.65)^{\mathrm{a}}$ & & $1.55(51,0.70)^{\mathrm{b}}$ & $1.57(51,0.70)^{\mathrm{b}}$ \\
Complex & $1.59(29,0.63)^{\mathrm{b}}$ & $1.69(29,0.71)^{\mathrm{b}}$ & & $2.03(29,0.91)^{\mathrm{c}}$ & $2.00(29,0.93)^{\mathrm{c}}$ \\
\hline
\end{tabular}

Notes. For Tables 4-10: Number of cases and standard deviations are in parentheses. Mean values with different superscripts indicate their being significantly different at $\alpha=0.10$ level, with two-tailed for comparisons between predicted and observed values and one-tailed for testing orders of values. In cases when Mean 1 and Mean 2, and Mean 2 and Mean 3 are not significantly different, respectively, but Mean 1 and Mean 3 are significantly different, Mean 3 may be given a different superscript if the $t$-value for Mean 3 and Mean 1 is larger than that for Mean 3 and Mean 2.

vided rich background on the importance of the environment (Aldrich 1979, Hannan and Freeman 1977), yet systematic explorations regarding how different types of task environments may have an impact on organizations of different designs are rare (Burton and Obel 2004, Lant and Mezias 1992).

Prediction 1. Based on CORP (Table 4), under usual situations an organization's performance is higher when facing a simple, compared with a complex, task environment. However, under a crisis situation, the opposite pattern is true $(\alpha=0.10)$. It is thus important to understand the trade-offs under different task environments before designing organizations, such as deciding on simple or complex forms. This approach is also advocated by various contingency theorists (Andres and Zmud 2002; Suchman 1987).

OBSERVATION 1 . The above predicted pattern is supported by the real crisis (or empirical) data $(\alpha=0.10)$. We need to keep in mind, however, that this result alone may not capture the whole picture, because many organizations may have shifted their designs and thus become more complex during crises.

\section{The Impact of Organizational Form}

We now ask whether the organizational design that exhibits good performance under usual conditions is also effective during a crisis. The literature also has provided numerous suggestions (Houskisson and Galbraith 1985, Jablin et al. 1986, Mackenzie 1978), but with little consistency across different conditions.

Prediction 2. Based on CORP (Table 5), under usual as well as crisis situations, organizational performance is not significantly different regardless of simple or complex organizational forms. This suggests organizational form alone may overlook some of the important internal factors such as processes and substandard conditions, and that it is important to jointly consider task environment factors. This is also consistent with the general contingency theory (Burton and Obel 2004).

OBSERVATION 2. The above pattern is supported by the empirical data $(\alpha=0.10)$.

The above result should be viewed with the understanding that performance is aggregated across a range of simple or complex organizational structures, which may have within-group differences due to their minor structural differences, if more fine-tuned analyses are followed. However, due to the scarcity of empirical data, it became necessary to aggregate some of the structural categories. Although aggregating the categories may lose some predictive power, it will enhance the validity of real data coding, because it minimizes the arbitrariness in classifying parameters in the real cases into too fine categories.

\section{The Impact of the Complexity Match Between Organizational Form and Task Environment}

In this study, we conduct an analysis on how the complexity match between organizational form and task environment may affect performance. Due to the scarcity of the real data, we create some more general categories. The studies by Carley and Lin (1997) and Lin and Carley (2003) included some more fine-tuned analyses of complexity match.

Prediction 3. Based on CORP (Table 6), under usual or crisis situations organizational performance is higher if there is a higher match between task environment and organizational form $(\alpha=0.10)$. This echoes the view by contingency theorists that advocates a fit between organizational form and task environment for

Table 5 The Effect of Organizational Form on Performance

\begin{tabular}{lccccc}
\hline & \multicolumn{2}{c}{ Usual performance } & & \multicolumn{2}{c}{ Crisis performance } \\
\cline { 2 - 3 } Organizational form & Prediction & Observation & & Prediction & Observation \\
\hline Simple & $1.77(52,0.67)^{\mathrm{a}}$ & $1.71(52,0.67)^{\mathrm{a}}$ & & $1.77(30,0.73)^{\mathrm{a}}$ & $1.63(30,0.85)^{\mathrm{a}}$ \\
Complex & $1.68(28,0.67)^{\mathrm{a}}$ & $1.79(28,0.69)^{\mathrm{a}}$ & & $1.70(50,0.86)^{\mathrm{a}}$ & $1.78(50,0.79)^{\mathrm{a}}$ \\
\hline
\end{tabular}


Table 6 The Effect of Complexity Match on Performance

\begin{tabular}{lccccc}
\hline & \multicolumn{2}{c}{ Usual performance } & & \multicolumn{2}{c}{ Crisis performance } \\
\cline { 2 - 3 } Complexity match & Prediction & Observation & & Prediction & Observation \\
\hline Low (mismatch) & $1.60(43,0.62)^{\mathrm{a}}$ & $1.70(43,0.64)^{\mathrm{a}}$ & & $1.56(41,0.78)^{\mathrm{a}}$ & $1.73(41,0.81)^{\mathrm{a}}$ \\
High (good match) & $1.89(37,0.70)^{\mathrm{b}}$ & $1.78(37,0.71)^{\mathrm{a}}$ & & $1.90(39,0.82)^{\mathrm{b}}$ & $1.72(39,0.83)^{\mathrm{a}}$ \\
\hline
\end{tabular}

better performance (Bigley and Roberts 2001, Burton and Obel 2004, Lawrence and Lorsch 1986).

ObSERVATION 3. This pattern is not supported due to the insignificant results in the empirical data, which suggests that more exploration is needed to extend current organizational theories to nonconventional events or crisis situations (Carley and Harrald 1997, Marcus and Nichols 1999).

\section{The Impact of Substandard Conditions}

We now look at how substandard operating conditions can affect organizational performance, which has been frequently mentioned in the organizational literature (Carley and Lin 1997, March and Olsen 1976).

Prediction 4. From CORP (Table 7), we see that generally as more things go wrong (there are more substandard conditions), organizational performance degrades $(\alpha=0.10)$. This suggests that substandard conditions can decrease the amount of incoming information and increase ambiguity and uncertainty in the decisionmaking process. Such effects were often as suggested, but not computationally explored or empirically tested, by other organization theorists (Jablin et al. 1986, March and Olsen 1976).

OBSERVATION 4. This pattern is generally supported by the empirical data that also show the impact of having even one substandard condition $(\alpha=0.10)$.

As mentioned in the model description section, we categorize substandard conditions into two major groups: information uncertainty and agent malfunction. In this study, we also examine cases when there are joint substandard conditions where both information uncertainty and agent malfunction may occur simultaneously.

Table 7 The Effect of Level of Substandard Conditions on Performance

\begin{tabular}{lcc}
\hline \multirow{2}{*}{$\begin{array}{l}\text { Number of substandard } \\
\text { conditions }\end{array}$} & \multicolumn{2}{c}{ Crisis performance } \\
\cline { 2 - 3 } None & Prediction & Observation \\
One & $2.33(12,0.49)^{\mathrm{a}}$ & $2.83(12,0.39)^{\mathrm{c}}$ \\
Two & $2.13(15,0.92)^{\mathrm{a}}$ & $2.00(15,0.85)^{\mathrm{a}}$ \\
Three & $1.68(31,0.75)^{\mathrm{b}}$ & $1.71(31,0.82)^{\mathrm{b}}$ \\
\hline
\end{tabular}

Notes. Under "None substandard operating conditions," performance is based on organization's usual performance when there is low frequency of prior similar causes. Under other operating conditions, performance is based on organization's crisis performance.
Prediction 5. Based on CORP (Table 8), little significant difference can be detected for the different types of substandard conditions $(\alpha=0.10)$. However, if we increase the sample size to 50 in each condition, we can find that agent malfunction and joint substandard conditions can create a significantly negative impact on organizational performance $(\alpha=0.10)$. This suggests that different types of substandard conditions can have different consequences to organizational performance under crisis situations, and that substandard conditions involving agents tend to have the most effect (Carley and Lin 1997, Jablin et al. 1986).

ObSERVATION 5. A similar pattern can be found from the real-world data $(\alpha=0.10)$. However, if we increase the sample size to 50 in each condition, we find that joint substandard conditions have the worst impact on organizational performance $(\alpha=0.10)$.

\section{Dynamic Adaptation in Crises}

Finally, let us consider the role of organizational restructuring. As noted in the introduction, it may not be reasonable to use the same organizational design under both crisis and usual conditions. Indeed, the designs that perform best under crises are not always the designs that perform best normally. Organizations in the corporate world may restructure under certain situations. The low correlation between usual performance and crisis performance in Table 3 also suggests that an organization's crisis performance may not depend on its usual performance; rather, it may depend on how it restructures during a crisis. Staw et al. (1981) argued that organizations are likely to become rigid when stressed and that such rigidity may improve organizational performance if the organization is facing a simple environment. This rigidity can be viewed as a movement to a more complex organization structure (such as a hierarchy) that is centralized, though not necessarily redundant. Other researchers advocate increasing structural

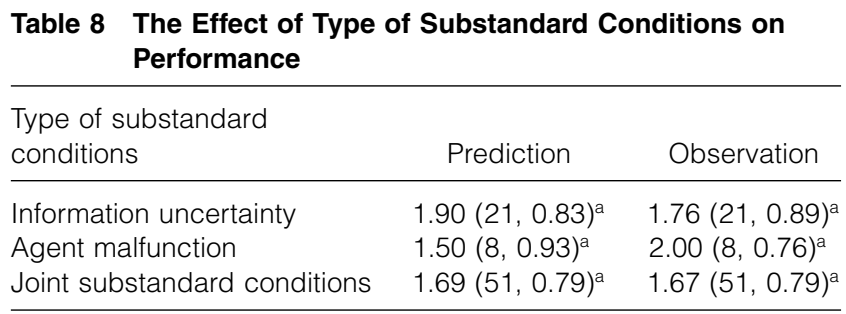


redundancy to decrease rigidity in access and maintain flexibility (La Porte and Consolini 1991, Mintzberg 1979, Roberts 1990, Thompson 1967). Still others (Shaw 1981) favor decentralized organizations as the design that can respond quickly to complex tasks and that therefore should perform better during crisis situations. These reviews suggest that it may be important to examine the relative value of organizational restructuring when organizations move from usual to crisis conditions.

We find that among the real organizations, 25 out of 80 altered their organizational forms when confronted with a crisis. Most organizations (23) switched toward more complex, though not necessarily more rigid, designs (Staw et al. 1981). These data support the argument that organizations faced with crises increase their structural redundancy. However, the data do not tell us whether this increase in redundancy has value and whether there could potentially be better structural changes. To answer these questions, we turn to a form of "what if" analysis. Using the computational model, we first examine the performance of these organizations under the conditions when they did or did not alter their designs. Then we explore if organizational designs exist that could have permitted the organization to perform better during the crisis situation. Thus, we can start to address two hypothetical but important questions: (a) What if the organizations had not altered their forms? and, (b) Of those organizations who experienced crises, what are better forms that they could have shifted to?

Prediction 6. CORP (Table 9) shows that there is no significant performance increase due to restructuring when changing from usual to crisis situations $(\alpha=0.10)$. In other words, the value of organizational restructuring in the face of a crisis may not be as scholars have expected (Carley and Hill 2001, Staw et al. 1981).

ObServation 6. The empirical data also support the pattern $(\alpha=0.10)$.

Using simulation, we can move a step beyond this finding and address the issue of "what if" no restructuring had happened.
Prediction 7. From CORP (Table 9), we see that there is virtually no performance benefit when organizations restructure during crises $(\alpha=0.10)$. In other words, organizations can maintain their performance if they retain their organizational form when faced with a crisis. This finding also echoes the suggestions by Brown and Eisenhardt (1998) on how adaptation may misfire. More importantly, this finding suggests that perhaps it is not the question of "whether" but "how" to restructure during crises that we should be asking.

PREDICTION 8. A further "what if" analysis from CORP (Table 10) shows that for those organizations that underwent crises, there exist better organizational designs to which they could have shifted. We can see that most organizations with a simple form could have benefited by adapting to a complex form. In contrast, most complex organizations may have already achieved their best possible performance given the situation, even though a few of them could also benefit by shifting to a simple form. This suggests that, during a crisis situation, organizations may face challenges of not just whether, but also how to adapt, since their first choice of adaptation may be subject to organizational design trap and may not yield the best possible outcomes for dealing with crises (Brown and Eisenhardt 1998).

Clearly these "what if" predictions cannot be tested with the particular empirical data we have used in this paper. However, the general fit between the model and the data suggests the plausibility of this analysis. Future work, in experimental or filed settings, might look at this issue in more detail (Lin 2000b).

\section{Discussion}

In this study, we take the stand that crises are essentially inevitable and that there is systematicity to their causes and consequences. We have adopted the neoinformation processing perspective and used a matched analysis to take a systematic, though exploratory, look at the relationships among organizational design, organizational performance, and crisis situations. Our study shows that sometimes a crisis can occur due to some seemingly minor miscues of the organizations, and that

Table 9 The Effect of Organizational Restructuring on Performance

\begin{tabular}{lccc}
\hline & & \multicolumn{2}{c}{ Crisis performance } \\
\cline { 3 - 4 } Type of shift & $\begin{array}{c}\text { Usual performance with } \\
\text { old form }\end{array}$ & $\begin{array}{c}\text { Restructured to } \\
\text { new form }\end{array}$ & If old form retained \\
\hline $\begin{array}{l}\text { Prediction } \\
\quad \text { No shift }\end{array}$ & $1.73(55,0.68)^{\mathrm{a}}$ & & $1.69(55,0.79)^{\mathrm{a}}$ \\
$\quad \begin{array}{l}\text { Shift } \\
\text { Observation }\end{array}$ & $1.76(25,0.66)^{\mathrm{a}}$ & $1.84(25,0.90)^{\mathrm{a}}$ & $1.80(25,0.87)^{\mathrm{a}}$ \\
$\quad$ No shift & $1.80(55,0.68)^{\mathrm{a}}$ & & $1.75(55,0.82)^{\mathrm{a}}$ \\
Shift & $1.60(25,0.65)^{\mathrm{a}}$ & $1.68(25,0.80)^{\mathrm{a}}$ & \\
\hline
\end{tabular}

Notes. An empty cell indicates that there are no data available. Number of cases and standard deviations are in parentheses. 
Table 10 Alternative Organizational Restructuring for Better Performance During Crises

\begin{tabular}{|c|c|c|c|}
\hline \multicolumn{4}{|c|}{ Prediction } \\
\hline $\begin{array}{l}\text { Current organizational } \\
\text { form during crisis }\end{array}$ & $\begin{array}{l}\text { Current crisis } \\
\text { performance }\end{array}$ & $\begin{array}{c}\text { Alternative organizational } \\
\text { restructuring* }\end{array}$ & $\begin{array}{l}\text { Potential crisis } \\
\text { performance }\end{array}$ \\
\hline Simple form & $\begin{array}{l}1.00(1,0.00)^{\mathrm{a}} \\
1.79(29,0.73)^{\mathrm{b}}\end{array}$ & $\begin{array}{l}\text { Stay as simple form } \\
\text { Shift to complex form }\end{array}$ & $\begin{array}{l}1.00(1,0.00)^{a} \\
2.28(29,0.73)^{c}\end{array}$ \\
\hline Complex form & $\begin{array}{l}1.74(46,0.88)^{\mathrm{b}} \\
1.25(4,0.50)^{\mathrm{a}}\end{array}$ & $\begin{array}{l}\text { Stay as complex form } \\
\text { Shift to simple form }\end{array}$ & $\begin{array}{l}1.74(46,0.88)^{b} \\
2.00(4,0.00)^{c}\end{array}$ \\
\hline
\end{tabular}

*Based on the best performing organization under a similar crisis condition.

if organizations are not properly designed to mitigate the impact of the crisis, disasters can happen. Our paper further demonstrates that not all organizational designs are best suited for both crisis and usual situations, and that while organizations often restructure when faced with a crisis, such adaptations may not be beneficial without understanding prior organizational design traps and the nature of the task environment. In addition, organizations may misinterpret the effect of altering their design.

In this paper, we have paid more attention to the formal aspects of organizational design. Following the work of Stinchcombe, we believe "formality and formalization have to do with abstraction so as to preserve what is essential in the substance" (2001, p. 3; italics in the original). Sociologists, for the most part, have generally regarded informality as a result of formal institutional arrangements (Zucker 1986) or "loose joint between different kinds of formality" (Stinchcombe 2001, p. 5). Child (1974) even suggested that informality is an unimportant mechanism that occurs due to some imperfect structural controls. From this sociological perspective, once organizations are set up, they can resort to structures and procedures to regulate their members' behaviors so the influence of informal characteristics will be minimized (Zucker 1986). While in other studies we examined some informal aspects of the organization, the findings have consistently shown the dominant effects of formal organizational factors (Lin and Carley 2003, Lin and Hui 1999).

\section{Main Contributions}

This study's results provide important insight into organizational performance under crisis conditions. First of all, this study has provided a new perspective to the field of crisis management. It views a crisis event as fundamentally an organizational issue and effectively demonstrates the benefit of adopting an organizational design approach to crisis management. In contrast to prior studies of crisis management, this study does not focus on the avoidance of crises, but rather on the mitigation of crisis impact. Furthermore, it highlights the importance for organizations to understand how, rather than whether, to restructure when facing a crisis. This approach is consistent with the view that crises may be, to some extent, unavoidable, given the increasing complexity of today's organization and the increasing competitiveness of today's environment. Our research demonstrates that a simple neo-information-processing model for examining organizational performance can reasonably well provide insight into and predict the behavior of human organizations in both crisis and noncrisis settings. Moreover, this study has implications beyond the field of crisis management. Although our research question centers on organizational designs under crisis situations, the findings are relevant to the broad field of strategic management.

Second, this study has provided a new and powerful approach by examining both artificial and real organizations with a matched analysis. Frequently, mathematical and computational models are presented without empirical data or empirical data are presented without a formal model. Formal modeling like ours is necessary for theory development. Empirical studies are necessary for testing theory. This paper, however, is relatively unique in that it enables an artificial-real comparison that is valuable, despite all the caveats about the limitations of the data set and the exactness of the fit between the artificial and the real organizations. This is a nontrivial feat, and few studies fall in this category. This kind of combined study is important so that we do not fall prey either to developing theories that build on theory rather than reality, or to developing ad hoc explanations of reality that do not consider underlying processes. From a validation standpoint, the matched analysis approach we used is also unique. Most validation studies focus on demonstrating that a set of hypotheses or general trends from the model hold in the empirical data across all of the data. Here we actually matched the simulated and real organizations, affording a more detailed level of validation. It also makes it possible for us to engage in a "what if" policy exploration using the validated model. As such, this study demonstrates an important use of computational analysis for theory building, moving into the realm of informed alternative state analysis ("what if" reasoning) (Burton and Obel 2004).

\section{Limitations and Future Research}

There are several limitations to this study. First, the model assumes that the organization is faced with a 
choice task and must choose between three options and that the agents in the organizations receive adequate feedback to learn. In the real world, however, the organization may or may not be facing a choice task, and even if it is facing a choice task there may be more than (or fewer than) three choices. Second, the data are drawn from multiple archival sources and there may be potential noise and bias in the coding of the cases due to the intents of the original authors. Moreover, the real-world organizations are often more complex in their design than the abstracted structures used in the computational model. While CORP allows the examination of many fine-tuned organizational characteristics such as types of training, no sufficient real crisis cases exist that allow us to examine them in a statistically valid way. Thus, the mapping between artificial and real organizations is not perfect. Furthermore, our analysis for the real organizations crosses multiple industries. Though we have attempted to control for industry features, there may still be problems in equating performance across different industries. In addition, our real organization cases only cover a small spectrum of the possible area, and many more cases could be examined using the computational model. Finally, because highly generalizable computational models often cannot be easily validated (Burton and Obel 1995), CORP is limited in its generalizability, which has enabled us to engage in the validation study presented. With the further development of computing technology and real-time data-capturing techniques, future studies should be able to consider more aspects of real-world environmental dimensions, organizational features, and individual characteristics building on complex system studies, organizational communications, and ethnography research (Siggelkow and Levinthal 2003, Taylor and Van Every 2000, Vromen 1995).

\section{Conclusion}

Despite the limitations discussed, we believe the approach used in this study and the results gained provide new directions for future theoretical, empirical, and methodological research. We have focused on organizational design and restructuring under crisis situations, and have provided systematic evidence for understanding the nature of organizational restructuring. The adaptation "what if" analysis where alternative possible states were examined is particularly telling. Our study suggests that the lessons that organizations learn when they adapt may be the opposite of the lessons they should be learning (Brown and Eisenhardt 1998). If this is the case, then the way in which organizations should be designed to encourage adaptation and the very nature of organizational adaptation need to be reconsidered in terms of the value of alternative paths, not just the value of the path taken.

\section{Acknowledgments}

The authors thank Senior Editor Rich Burton and two anonymous reviewers of Organization Science for their constructive comments on earlier versions of the manuscript, of which a short version was included in the 2001 Academy of Management Best Papers Proceedings, Washington, D.C. We also thank Douglas Wholey, Richard Harrison, and three anonymous reviewers of the 2001 Academy of Management Annual Meeting for their helpful feedback, as well as Dung Hua for her editorial assistance.

\section{Appendix. A General Algorithm for CORP}

STEP 1. Experimental Setting

Set experimental context through the selection of task environment, organizational structure, resource access structure, and internal operating condition.

- Select one of the task environments, with 1 for concentrated decomposable, 2 for concentrated nondecomposable, 3 for dispersed decomposable, and 4 for dispersed nondecomposable.

- Select one of the organizational structures, with 1 for team with voting, 2 for team with a manager, 3 for hierarchy, and 4 for matrix.

- Select one of the resource access structures, with 1 for segregated, 2 for overlapped, 3 for blocked, and 4 for distributed.

- Select one of the training types for decision making, with 0 for no training (as a baseline), 1 for operational training, and 2 for experiential training. (Due to the scarcity of the real-world cases, operational and experiential training types have been combined in this study.)

- Select one type of substandard operating conditions, with 1 for missing information, 2 for incorrect information, 3 for agent unavailability, 4 for communication down, and 5 for agent turnover.

- Select one level of substandard operating conditions, with 0 for none (standard operating condition), 1 for one, 2 for two, and 3 for three.

- Record all selected parameters (each unique combination is one experimental setting).

STEP 2. Problem Generation

Generate a series of radar detection task problems, each having nine components (indicators) that can be coded into 1,2 , or 3 , for the organization to process under the selected experimental setting.

Step 3. Base-Level Decision Processes

Each bottom-level analyst accesses a subset of the nine problem components as specified by the organization structure, makes a decision using the selected decision-making procedure, and passes the recommendation to his designated manager. This process may also be affected by some of the operating conditions chosen earlier.

- Each base-level analyst accesses a subset of the nine problem components as specified by the resource access structure.

$>$ If the resource access structure is segregated, each baselevel analyst will access only one problem component, with no overlap.

$>$ If the resource access structure is overlapped, each baselevel analyst will access two problem components, with one component overlapped with a nearby analyst. 
If the resource access structure is blocked, each base-level analyst will access three problem components, with all three components overlapped with the two analysts within the same subunit.

$>$ If the resource access structure is distributed, each baselevel analyst will access three problem components, with each component being accessed by three different analysts from three different subunits.

—Each base-level analyst makes a recommendation on her subset of the problem information using the specified decision mechanism.

$>$ If missing information occurs with one or more pieces of incoming information, the base-level analyst will rely on only the remaining pieces of information.

$>$ If incorrect information occurs with one or more pieces of incoming information, the base-level analyst will rely on all the information as if nothing is wrong, as he is not aware of the substandard operating condition.

- If the decision procedure is based on no training, recommendation is based on a random choice between 1 and 3.

- If the decision procedure is operationally trained, recommendation is based on the majority rule of currently available information.

- If the decision procedure is experientially trained, recommendation is based on how often the same pattern of information has occurred in the past.

- Each base-level analyst passes the recommendation to her designated manager as specified by the organization structure.

$>$ If the structure is a team with voting, the recommendation is passed to a pseudo-top-level manager directly (for calculating the majority voting result later).

$>$ If the structure is a team with a manager, the recommendation is passed to the top-level manager directly.

$>$ If the structure is a hierarchy, the recommendation is passed to one designated middle-level manager.

$>$ If the structure is a matrix, the recommendation is passed to one designated middle-level manager and another middle-level manager of a different subunit.

Step 4. Middle-Level Decision Processes

Each middle-level manager reads recommendations from his subordinates as specified by the organization structure, makes a decision using the selected decision-making procedure, and passes the recommendation to the top-level manager. This process may also be affected by some of the operating conditions chosen earlier. If the organization structure is a team structure, skip Step 4 and go to Step 6.

- Each middle-level manager reads recommendations from his subordinates as specified by the organizational structure.

$>$ If agent unavailability occurs at one or more subordinate positions, the middle-level manager will rely on only the remaining subordinates for recommendations.

$>$ If communication channel breakdown occurs at one or more channels, the middle-level manager will rely on only the remaining channels for subordinates for recommendations.

$>$ If agent turnover occurs at one or more subordinate positions, the middle-level manager will treat each new subordinate's recommendation as a random recommendation.
- Each middle-level manager makes a recommendation on her collected information using the specified decision mechanism.

$>$ If the decision procedure is based on no training, recommendation is based on a random choice between 1 and 3 .

$>$ If the decision procedure is operationally trained, recommendation is based on the majority rule of currently available information.

$>$ If the decision procedure is experientially trained, recommendation is based on how often the same pattern of information has occurred in the past.

- Each middle-level manager passes the recommendation to the top-level manager as specified by the organization structure.

Step 5. Top-Level Decision-Making Processes

The top-level manager reads recommendations from his subordinates as specified by the organizational structure, and makes the final decision using the selected decision-making procedure. A pseudo-top-level manager is used for team with voting structure as a special case.

- The top-level manager reads recommendations from her subordinates as specified by the organization structure.

$>$ If the structure is a team with voting, the pseudo-toplevel manager reads information from the nine base-level analysts.

$>$ If the structure is a team with a manager, the top-level manager reads information from the nine base-level analysts.

$>$ If the structure is a hierarchy, the top-level manager reads information from the three middle-level managers.

- The top-level manager makes a decision on his collected information using the specified decision mechanism.

$>$ If the organizational structure is a team with voting, the pseudo-top-level manager will simply tabulate the majority vote based on the recommendations from all the baselevel analysts. Otherwise:

- If the decision procedure is based on no training, decision is based on a random choice between 1 and 3 .

- If the decision procedure is operationally trained, decision is based on the majority rule of currently available information.

- If the decision procedure is experientially trained, decision is based on how often the same pattern of information has occurred in the past.

- The top-level manager registers the decision as the organizational decision.

- If this is the last problem of the series under this experimental setting, go to Step 6. Otherwise, go to Step 3.

Step 6. Performance Feedback Processes

The model registers the top-level manager's final decision as the organization's decision and calculates the true nature of the problem based on the formula from the specified task environment. The computer then compares the organizational decision with the true nature of the problem, records the comparison results, and provides feedback to the whole organization.

- Calculation of the true nature of the problem based on the formula for the specified task environment.

$>$ If type of task environment is 1 (concentrated decomposable):

- Sum $=t 1+t 2+t 3+t 4+t 5+t 6+t 7+t 8+t 9$.

- If $\operatorname{sum} \leq 13$, true nature of problem is friendly. 
-If $13<$ sum $\leq 17$, true nature of problem is neutral.

- If sum $>17$, true nature of problem is hostile.

If type of task environment is 2 (concentrated nondecomposable):

- $\mathrm{Sum}=t 1 * t 2 * t 3 * 2+t 4 * t 5 * 2+t 6 * t 7 * t 9 * 2+t 8$ $+t 9$.

- If sum $\leq 20$, true nature of problem is friendly.

- If $20<$ sum $\leq 23$, true nature of problem is neutral.

- If sum $>23$, true nature of problem is hostile.

If type of task environment is 3 (dispersed decomposable):

- Sum $=t 1+t 2+t 3+t 4+t 5+t 6+t 7+t 8+t 9$.

- If sum $\leq 16$, true nature of problem is friendly.

- If $16<$ sum $\leq 19$, true nature of problem is neutral.

- If sum $>19$, true nature of problem is hostile.

If type of task environment is 4 (dispersed nondecomposable):

- Sum $=t 1 * t 2 * t 3 * 2+t 4 * t 5 * 2+t 6 * t 7 * t 9 * 2+t 8+$ $t 9$.

- If sum $\leq 20$, true nature of problem is friendly.

- If $20<$ sum $\leq 23$, true nature of problem is neutral.

- If sum $>23$, true nature of problem is hostile.

— Calculation of organizational performance.

If overall performance is desired:

- Count number of total problems.

- Count number of correct decisions.

- Calculate performance in terms of decision-making accuracy based on number of correct decisions over number of problems.

$>$ If performance under external stress is desired:

- Count number of problems with true state as hostile.

- Count number of correct decisions made when the problem's true state is hostile.

- Calculate performance under critical external situations in terms of decision-making accuracy based on number of correct decisions over number of problems when the true state is hostile.

\section{Endnote}

${ }^{1}$ A detailed codebook, describing the coding of each variable of organizational design, crisis factors, and organizational performance, was constructed and is available on request. Codebook entries provide criteria for making the coding judgment, as will be further illustrated later. They also contain numerous case examples. In another study, the coding of two cases, the Vincennes incident and the Hinsdale incident, was described in lengthy detail using similar coding mechanisms (Lin 2000a). Two new co-authors, who previously had no knowledge of the research, coded these cases using the codebook. For the 2,080 items that require subjective coding in the 80 cases, the interrater reliability is $85.0 \%$.

\section{References}

Aldrich, H. E. 1979. Organizations and Environment. Prentice Hall, Englewood Cliffs, NJ.

Anderson, P., M. L. Tushman. 2001. Organizational environments and industry exit: The effects of uncertainty, munificence and complexity. Indust. Corporate Change 10(3) 6705-6711.

Andres, H. P., R. W. Zmud. 2002. A contingency approach to software project coordination. J. Management Inform. Systems 18(3) 4170.

Baligh, H. H., R. M. Burton, B. Obel. 1990. Devising expert systems in organization theory: The organizational consultant. Michael Masuch, ed. Organization, Management, and Expert Systems. Walter De Gruyter, Berlin, Germany, 35-57.

Bigley, G. A., K. H. Roberts. 2001. The incident command system: High-reliability organization for complex and volatile task environments. Acad. Management J. 44(6) 1281-1300.

Brown, S. L., K. M. Eisenhardt. 1998. Competing on the Edge: Strategy as Structured Chaos. Harvard Business School Press, Boston, MA.

Burton, R. M., B. Obel. 1995. The validity of computational models in organizations science: From model realism to purpose of the model. Comput. Math. Organ. Theory 1(1) 57-71.

Burton, R. M., B. Obel. 2004. Strategic Organizational Diagnosis and Design: The Dynamics of Fit, 3rd ed. Kluwer Academic, Boston, MA.

Campbell, D. T. 1975. Degrees of freedom and the case study. Comparative Political Stud. 8 178-193.

Carley, K. M. 1996. A comparison of artificial and human organizations. J. Econom. Behav. Organ. 31(2) 175-191.

Carley, K. M., J. R. Harrald. 1997. Organizational learning under fire: Theory and practice. Amer. Behav. Scientist 40(3) 310-332.

Carley, K. M., V. Hill. 2001. Structural change and learning within organizations. Alessandro Lomi, Erik R. Larsen, eds. Dynamics of Organizations: Computational Modeling and Organizational Theories. MIT Press/AAAI Press, Cambridge, MA, 63-92.

Carley, K. M., Z. Lin. 1995. Organizational designs suited to high performance under stress. IEEE Trans. Systems, Man, Cybernetic 25(2) 221-230.

Carley, K. M., Z. Lin. 1997. A theoretical study of organizational performance under information distortion. Management Sci. 43(7) 976-997.

Carley, K. M., M. J. Prietula. 1994. ACTS theory: Extending the model of bounded rationality. Kathleen Carley, Michael Prietula, eds. Computational Organization Theory. Lawrence Erlbaum Associates, Hillsdale, NJ, 55-88.

Carley, K. M., M. J. Prietula, Z. Lin. 1998. Design versus cognition: The interaction of agent cognition and organizational design on organizational performance. J. Artificial Soc. Soc. Simulation 1(3) $1-19$.

Child, J. 1974. What determines organizational performance? The universals vs. it-all-depends. Organ. Dynam. 3(Summer) 2-18.

Cohen, K. J., R. M. Cyert. 1965. Simulation of organizational behavior. J. G. March, ed. Handbook in Organizations. Rand McNally, Chicago, IL, 305-334.

Cohen, M. D., J. G. March, J. P. Olsen. 1972. A garbage can model of organizational choice. Admin. Sci. Quart. 17(1) 1-25.

Courtright, J. A., G. T. Fairhurst, L. E. Rogers. 1989. Interaction patterns in organic and mechanistic systems. Acad. Management $J$. 32(4) 773-802. 
Daft, R. L., K. E. Weick. 1984. Toward a model of organizations as interpretation systems. Acad. Management Rev. 9(2) 284-295.

Davis, S. M., P. R. Lawrence. 1977. Matrix. Addison Wesley, Reading, MA.

Dill, W. R. 1958. Environment as an influence on managerial autonomy. Admin. Sci. Quart. 2 409-443.

Duffy, B., R. Kaylor, P. Cary. 1988. How good is this navy, anyway? U.S. News and World Report (July 18).

Dunbar, R., S. A. Stumpf. 1989. Trainings that demystify strategic decision-making processes. J. Management Development 8(1) $36-42$.

Eisenhardt, K. M. 1989. Building theories from case study research. Acad. Management Rev. 14(4) 532-550.

Galbraith, J. R. 1977. Organization Design. Addison Wesley, Reading, MA.

Green, F. E. 1989. When just-in-time breaks down on the line. Indust. Management 31(1) 26-29.

Hannan, M. T., J. Freeman. 1977. The population ecology of organizations. Amer. J. Sociol. 82 929-964.

Health and Safety Executive. 2001. Flixborough, Nypro UK Explosion, 1 June 1974. Health and Safety Executive. Hazardous Installations Directorate, London, UK. http://www.hse.gov.uk.

Hermann, C. F. 1963. Some consequences of crisis which limit the viability of organizations. Admin. Sci. Quart. $8343-358$.

Hollenbeck, J. R., D. R. Ilgen, D. Tuttle, D. J. Sego. 1995. Team performance on monitoring tasks: An examination of decision errors in contexts requiring sustained attention. J. Appl. Psych. 80 685-696.

Houskisson, R. E., C. S. Galbraith. 1985. The effect of quantum versus incremental $\mathrm{m}$-form reorganization on performance: A time series exploration of intervention dynamics. J. Management 11 $55-70$.

Hutchins, E. 1991. Organizing work by adaptation. Organ. Sci. 2(1) 14-39.

Jablin, F. M., L. L. Putnam, K. H. Roberts, L. W. Porter, eds. 1986. Handbook of Organizational Communication: An Interdisciplinary Perspective. Sage, Beverly Hills, CA.

Klein, K. J., H. Tosi, A. A. Cannella, Jr. 1999. Multilevel theory building: Benefits, barriers, and new developments. Acad. Management Rev. 24(2) 243-248.

Lagadec, P. 1981. Major Technological Risk: An Assessment of Industrial Disasters. Pergamon Press, New York.

Lant, T. K., S. J. Mezias. 1992. An organizational learning model of convergence and reorientation. Organ. Sci. 3 47-71.

La Porte, T. R., P. M. Consolini. 1991. Working in practice but not in theory: Theoretical challengers of "high-reliability organizations." J. Public Admin. Res. Theory 1(1) 19-47.

Lawrence, P. R., J. W. Lorsch. 1986. Organization and Environment: Managing Differentiation and Integration. Harvard Business School Press, Cambridge, MA.

Levinthal, D. A., M. Warglien. 1999. Landscape design: Designing for local action in complex worlds. Organ. Sci. 10(3) 342-357.

Lin, Z. 2000a. Organizational performance under critical situations: Exploring the role of computer modeling in crisis case analyses. Comput. Math. Organ. Theory 6(3) 277-310.

Lin, Z. 2000b. Organizational restructuring and the impact of knowledge transfer. J. Math. Sociol. 24(2) 129-149.
Lin, Z., M. Carley. 1995. DYCORP: A computational framework for examining organizational performance under dynamic conditions. J. Math. Sociol. 20(2-3) 193-217.

Lin, Z., M. Carley. 1997. Organizational response: The cost performance tradeoff. Management Sci. 43(2) 217-234.

Lin, Z., M. Carley. 2003. Designing Stress Resistant Organizations: Computational Theorizing and Crisis Applications. Kluwer Academic Publishers, Boston, MA.

Lin, Z., C. Hui. 1999. Should lean replace mass organization systems: A theoretical examination from a management coordination perspective. J. Internat. Bus. Stud. 30(1) 45-80.

Mackenzie, K. D. 1978. Organizational Structures. AHM Publishing Corporation, Arlington Heights, IL.

Mantzavinos, C. 2001. Individuals, Institutions, and Markets. Cambridge University of Press, Cambridge, UK.

March, J. G., J. P. Olsen. 1976. Ambiguity and Choice in Organizations. Universitetsforlaget, Bergen, Germany.

March, J. G., H. A. Simon. 1958. Organizations. John Wiley \& Sons, New York.

March, J. G., L. S. Sproull, M. Tamuz. 1991. Learning from the samples of one or fewer. Organ. Sci. 2(1) 1-13.

Marcus, A. A., M. L. Nichols. 1999. On the edge: Heeding the warning of unusual events. Organ. Sci. 10(4) 482-499.

Miles, R. E., W. E. D. Creed. 1995. Organizational forms and managerial philosophies: A descriptive and analytical review. B. M. Staw, L. L. Cummings, eds. Research in Organizational Behavior 17. JAI Press, Greenwich, CT, 333-372.

Mintzberg, H. 1979. The Structure of Organizations. Prentice Hall, Englewood Cliffs, NJ.

Newell, A. 1990. Unified Theories of Cognition. Harvard University Press, Cambridge, MA.

Pauchant, T. C., R. Douville. 1993. Recent research in crisis management: A study of 24 authors' publications from 1986 to 1991. Indust. Environ. Crisis Quart. 7 43-61.

Pearson, C. M., J. A. Clair. 1998. Reframing crisis management. Acad. Management Rev. 23(1) 59-76.

Pearson, C. M., I. I. Mitroff. 1993. From crisis prone to crisis prepared: A framework for crisis management. Acad. Management Executive 7(1) 48-59.

Perrow, C. 1984. Normal Accidents: Living with High Risk Technologies. Princeton University Press, Princeton, NJ.

Perrow, C. 1986. Complex Organizations: A Critical Essay. Scott, Foresman and Company, Glenview, IL.

Perrow, C. 1994. The limits of safety: The enhancement of a theory of accidents. J. Contingencies Crisis Management 4(2) 212-220.

Pfeffer, J., G. R. Salancik. 1978. The External Control of Organizations. Harper and Row, New York.

Reason, J. 1998. Broadening the cognitive engineering horizons: More engineering, less cognition, and no philosophy of science, please. Ergonomics 41(2) 150-152.

Roberts, K. H. 1990. Some characteristics of one type of high reliability organizations. Organ. Sci. 1(2) 160-176.

Roberts, N. C., K. Dotterway. 1995. The Vincennes incident: Another player on the stage? Defense Anal. 11(1) 31-45.

Rochlin, G. I. 1991. Iran Air Flight 655 and the USS Vincennes: Complex, large-scale military systems and the failure of control. Todd R. La Porte, ed. Social Responses to Large Technical Systems: Control or Anticipation. Kluwer Academic Publishers, Amsterdam, The Netherlands.

Rolfe, J., D. Saunders, T. Powell, eds. 1998. Simulation and Games for Emergency and Crisis Management. Kogan Page, London, UK. 
Rosenthal, U., B. Pijnenburg. 1991. Crisis Management and Decision Making: Simulation Oriented Scenarios. Kluwer Academic, Boston, MA.

Rousseau, D. M., R. J. House. 1994. Meso organizational behavior: Avoiding the fundamental biases. J. Organ. Behav. 1 13-30.

Schlager, N., N. Schlager. 1994. When Technology Fails. Significant Disasters, Accidents, and Failures of the Twentieth Century. Gale Research, Inc. Detroit, MI.

Scott, W. R. 1987. Organizations: Rational, Natural, and Open Systems. Prentice Hall, Englewood Cliffs, NJ.

Shaw, M. E. 1981. Group Dynamics: The Psychology of Small Group Behavior. McGraw-Hill, New York.

Shrivastava, P. 1987. Bhopal: Anatomy of a Crisis. Ballinger Publishing, Cambridge, MA.

Siggelkow, N., D. A. Levinthal. 2003. Temporarily divide to conquer: Centralize, decentralized, and reintegrated organizational approaches to exploration and adaptation. Organ. Sci. 14(6) 650-669.

Siggelkow, N., J. Rivkin. 2005. Speed and search: Designing organizations for turbulence and complexity. Organ. Sci. 16(2) $101-122$.

Simon, H. A. 1947. Administrative Behavior. Free Press, New York.

Simon, H. A. 1962. The architecture of complexity. Proc. Amer. Philos. Soc. 106(6) 467-482.

Simon, H. A. 1973. Applying information technology to organizational design. Public Admin. Rev. 33 268-278.

Staw, B. M., L. E. Sanderlands, J. E. Dutton. 1981. Threat-rigidity effects in organizational behavior: A multilevel analysis. Admin. Sci. Quart. 26 501-524.

Stinchcombe, A. L. 2001. When Formality Works: Authority and Abstraction in Law and Organizations. University of Chicago Press, Chicago, IL.

Suchman, L. A. 1987. Plans and Situated Actions: The Problem of Human Machine Communication. Cambridge University Press, Cambridge, UK.
Tamminga, H., T. S. Kilijanek, C. Adams. 1981. Managing MultiOrganizational Emergency Responses. University of Colorado Press, Seven Springs, CO.

Taylor, J. R., E. J. Van Every. 2000. The Emergent Organization: Communication as Its Site and Surface. Lawrence Erlbaum Associates, Mahwah, NJ.

Thompson, J. D. 1967. Organizations in Action. McGraw-Hill, New York.

Thompson, M. B. 1994. Expanding simulation beyond planning and design. Indust. Engrg. 26(10) 64-66.

U.S. Congress. 1988. Air flight 655 compensation hearings before the Defense Policy Panel of the Committee on Armed Services, House of Representatives, 2nd session (held August 3-4, September 9, October 6). U.S. Government Printing Office, Washington, D.C.

Vromen, J. J. 1995. Economic Evolution: An Enquiry into the Foundations of New Institutional Economics. Routledge, London, UK.

Walker, W. E. 1995. The Use of Scenarios and Gaming in Crisis Management Planning and Training. RAND, Santa Monica, CA.

Watson, R., J. Barry, R. Sandza. 1988. A case of human error. Newsweek (August 15).

Weick, K. E. 1969. The Sociology Psychology of Organizing, 2nd ed. Addison-Wesley, Reading, MA.

Weick, K. E., K. H. Roberts. 1993. Collective minds in organizations: Heedful interacting on flight decks. Admin. Sci. Quart. 38 357-381.

Yin, R. K. 1994. Case Study Research: Design and Methods. Sage, Thousand Oaks, CA.

Zey-Ferrell, M. 1979. Dimensions of Organizations: Environment, Context, Structure, Process, and Performance. Goodyear Publishing Company, Santa Monica, CA.

Zucker, L. G. 1986. Production of trust: Institutional sources of economic structure, 1840-1920. B. M. Staw, L. L. Cummings, eds. Research in Organizational Behavior 8. JAI Press, Greenwich, CT, 53-111. 